\title{
ALGUNAS CONSIDERACIONES SOBRE LA INVESTIGACIÓN JURÍDICA EN MÉXICO
}

\author{
Rafael SÁNCHEZ VÁZQueZ \\ Profesor-Investigador de la Facultad \\ de Derecho y Ciencias Sociales \\ Benemérita Universidad Autónoma de Puebla \\ Investigador Nacional Nivel III \\ del Sistema Nacional de Investigadores \\ rsva7@hotmail.com
}

\begin{abstract}
RESUMEN
Los nuevos paradigmas de la ciencia jurídica nos obligan a integrarnos a una dinámica del proceso enseñanza-aprendizaje más creativa y problematizadora del conocimiento jurídico. Las nuevas generaciones de estudiosos de la ciencia jurídica se deben preocupar y ocupar por estudiar y analizar las diferentes corrientes teórico-metodológicas del Derecho (por ejemplo, el realismo jurídico, el estructuralismo jurídico, la sociología jurídica aplicada) y no excederse de manera dogmática y exclusiva al estudio del positivismo decimonónico jurídico. Las facultades y escuelas de Derecho que ofertan sus estudios en la República mexicana se caracterizan, en términos generales, por conservar la enseñanza tradicional del Derecho. De abi la escasez de juristas que se dediquen a la investigación jurídica de práctica cientifica.
\end{abstract}

Palabras clave: investigación jurídica, investigadores nacionales, enseñanza tradicional, cultura jurídica, ciencia jurídica, formalismo jurídico, realismo jurídico, estructuralismo jurídico, sociología jurídica aplicada.

\section{ABSTRACT}

The new models of legal science get us involved in a more creative and complex dynamics of the learning-teaching process and the legal know-bow. The new generations of legal science scholars must worry and study the several theories of both theoretical and methodological laws such as legal realism, legal structuralism, applied legal sociology and they should not exceed their dogmatism and exclusivity to the law of 19th Century. Faculties and Law Schools which offer their studies in the Republic of Mexico usually stick to the old school. Therefore there is a lack of lawyers devoted to the study of science practice on a legal basis.

Keywords: Legal research, national researchers, traditional teaching, legal knowledge, legal science, legal formalism, legal realism, legal structuralism, legal applied sociology. 


\section{ZUSAMMENFASSUNG}

Die neuen Paradigmen der Rechtswissenschaft nötigen uns beim Erwerb juristischen Wissens dazu, uns in eine kreativere und problemorientiertere Dynamik. des Lebrens-Lernens einzugliedern. Die neuen Generationen der Rechtsgelebrten sollten darum bemüht sein, die verschiedenen theoretisch-methodologischen Strömungen des Rechts, z.B. des juristischen Realismus, den juristischen Strukturalismus sowie die angewandte juristische Soziologie zu studieren und zu analysieren. Andererseits sollten sie nicht dogmatisch und ausschliesslich den juristischen Positivismus des 19. Jabrbunderts vertreten. Die juristischen Fakultäten und Schulen der Republik Mexiko zeichnen sich dadurch aus, dass sie die traditionelle juristische Lebre bewabren. Darin liegt der Grund, dass es nur wenige Juristen gibt, die sich der juristischen Forschung und der wissenschaftlichen Praxis widmen.

Schlüsselwörter: Juristische Forschung, nationale Forscher, tradtionelle Lehre, juristische Kultur, Rechtswissenschaft, juristischer Formalismus, juristischer Realismus, juristischer Strukturalismus, angewandte juristische Soziologie.

SUMARIO: I. PRESENTACIÓN.-II. ALGUNAS CONSIDERACIONES SOBRE LA DOCENCIA JURÍDICA EN LA NUEVA ESPAÑA.-III. LA DOCENCIA JURÍDICA EN EL MÉXICO INDEPENDIENTE.-IV. DIAGNÓSTICO ACTUAL SOBRE LA INVESTIGACIÓN JURÍDICA EN MÉXICO.V. REFLEXIONES FINALES.-VI. BIBLIOGRAFÍA.

«El modelo de la universidad napoleónica ha impactado en la información y formación de los estudiosos del Derecho en México reforzando el perfil profesionalizante alejado de la generación del conocimiento y, por ende, de la investigación jurídica de práctica científica. Lamentablemente, la visión disciplinaria tan arraigada y la docencia tradicional del Derecho obstaculizan, por un lado, el cambio y, por otra parte, la construcción de nuevos paradigmas, y perpetúan la concepción decimonónica del Derecho positivista vía la exégesis. Consecuentemente, aún se perciben lejanas las investigaciones interdisciplinarias y transdiciplinarias del conocimiento jurídico».

Rafael SÁnCHEZ VÁzQuez 


\section{PRESENTACIÓN}

En la República mexicana se tiene una población aproximada de 119 millones de habitantes. De dicha población, aproximadamente 8.500.000 tienen cédula profesional de licenciatura en las diferentes disciplinas (física, química, biología, astronomía, historia, economía, sociología, derecho, etc.). De este universo de profesionistas se tienen 685.000 profesionistas de la licenciatura en Derecho con cédula profesional. Empero, quienes se dedican a la investigación jurídica representan un grupo reducido. De ahí que identificamos a tan sólo 427 de estos profesionistas que se dedican a la investigación jurídica de manera permanente y continua. Lo cual representa el porcentaje del 0,062 por 100 registrados por el padrón de investigadores del Sistema Nacional de Investigadores del CONACyT-SEP en México (en sus diferentes niveles: eméritos, nivel III, nivel II, nivel I y candidatos a investigador nacional).

Por otra parte cabe resaltar que la deficiencia de investigadores nacionales en la disciplina del Derecho obedece a varios factores y son, a saber:

1. La presencia hegemónica del positivismo jurídico decimonónico a través del excesivo formalismo de la exégesis, lo cual ha obstaculizado, por una parte, impulsar la investigación jurídica y a quienes se dedican a dicha actividad, y, por otra, se limita la creatividad y generación del conocimiento jurídico de frontera.

$\mathrm{Al}$ respecto, el jurista hispano Antonio Hernández Gil expresa:

«El Derecho positivo lo es todo y todo el derecho positivo está constituido por la ley; culto, pues al texto de la ley, sumisión absoluta. Son ya famosas las palabras de Bugnet: "Yo no conozco el Derecho civil y no enseño más que el Código de Napoleón”» .

Por su parte, Chaïm Perelman considera:

«Proclamar la omnipotencia del legislador y la creencia en su infalibilidad nos conlleva a una apreciación errónea de la realidad, ya que existen lagunas en algunas leyes de esta suerte. La percepción de una laguna en la ley significa claramente, para el juez, que la solución no se puede obtener

${ }^{1}$ A. Hernández Gil, Metodología de la Ciencia del Derecho, vol. I, 1. a ed., Madrid, Gráficas Unguina Meléndez Valdez, 1971, pp. 81 y 82. 
por medio de una deducción hecha a partir de un texto legal. Si, no obstante, debe llenar la laguna y motivar su decisión, es claro que sólo podrá llegar a este resultado recurriendo a formas de razonamiento que no sean las de la lógica formal» ${ }^{2}$.

Ahora bien, las reflexiones antes mencionadas nos permiten comprender con claridad y precisión que el positivismo decimonónico del Derecho ha frenado la formación de investigadores de las ciencias jurídicas, ya que sólo forma, en términos generales, técnicos que interpretan y aplican exegéticamente el Derecho. Es decir, son codigueros mediante el imperio autoritario de la ley. De ahí que Perelman expresa:

«En una sociedad democrática es imposible mantener la visión positivista (exegética) según la cual el Derecho no es otra cosa que la expresión arbitraria de la voluntad del soberano. Para funcionar eficazmente, el Derecho debe ser aceptado y no sólo impuesto por medio de la coacción» ${ }^{3}$.

Para Ramón Badenes, «el método exegético jurídico, al analizar los textos, llega con mayor frecuencia al casuismo; resuelve cómodamente el problema del concepto de Derecho afirmando qué es lo que se da: la ley, llegando a un máximo de positivismo y racionalismo prescindiendo de consideraciones sociológicas o económicas. Y, en definitiva, no recompone, no sistematiza ni construye, agotándose en la deducción y en el análisis» ${ }^{4}$.

Consecuentemente, lo que ahora hace falta para impulsar y aumentar el número de estudiosos de la investigación jurídica en México es integrarse a través de planes de estudios con sus respectivos programas académicos alejados de la parcelación del conocimiento disciplinario. Ahora se requiere, a través de la multidisciplinariedad, la plurisdisciplinariedad, la interdisciplinariedad y la transdisciplinariedad, adentrarse en la complejidad del conocimiento a la que estamos convocados los juristas del presente y del porvenir, ya que no podemos renunciar a los grandes retos epistemológicos que se están generando en el presente si es que pretendemos recobrar la identidad de intelectuales preocupados en la construcción del conocimiento y su vinculación con la dinámica social y el avance científico y tecnológico.

2 C. Perelman, La lógica jurídica y la nueva retórica, trad. esp. de Luis Díez-Picazo, Madrid, Civitas, 1979, p. 65.

3 Ibid., p. 231.

${ }^{4}$ R. Badenes Gasset, Metodología del Derecho, Barcelona, Bosch, 1979, p. 95. 
2. En las facultades y escuelas de Derecho de la República mexicana persiste la enseñanza tradicional del Derecho en sus diferentes programas educativos, tanto de la licenciatura como del posgrado de Derecho. Lamentablemente, el modelo de la docencia tradicional del Derecho descansa en el paradigma del materialismo mecanicista del conocimiento, en donde el alumno o sujeto cognoscente tiene una conducta pasiva, receptiva, acrítica, contemplativa y repetitiva, ya que reproduce la información que le proporciona el profesor de manera memorizada e irreflexiva. De ahí que el docente establece una relación autoritaria, vertical, domesticante, a través de un monólogo estéril y alienante, hasta llegar al extremo de ser un dictador de apuntamientos. No existe diálogo ni discusión, y menos debate académico, entre el profesor y los alumnos, toda vez que ni el educador ni el educando investigan. Consecuentemente, no existe la generación del conocimiento, razón por la cual ambos reproducen incondicionalmente la concepción decimonónica del Derecho, que surge y se desarrolla tanto su auge como su decadencia en el siglo XI. Dicha problemática existe y persiste en más de 950 instituciones de educación superior que ofertan sus estudios de Derecho en la República mexicana.

$\mathrm{Al}$ respecto, Miguel Carbonell comenta lo siguiente:

«La realidad amenaza con volver obsoletos un porcentaje importante de los conocimientos que se transmiten. En las escuelas y facultades de Derecho se sigue teniendo un modelo puramente normativo del Derecho, es decir, una visión que, en la búsqueda mal entendida de la "pureza" metódica, considera que no debe hacer caso a ningún tipo de manifestación extranormativa de lo que realmente sucede en la sociedad. No se estudian todas las fuentes del Derecho, ni siquiera todas las fuentes "formales" que contempla el ordenamiento. La atención se centra en las leyes y códigos, se dedica muy poco tiempo a los tratados internacionales, algo a la jurisprudencia nacional (aunque por lo general no se realizan estudios de casos, sino que se mencionan simplemente los criterios interpretativos que han sostenido los órganos judiciales) y no se presta atención alguna a la jurisprudencia internacional. Urge revisar casi todo: desde los libros con los que se enseña, hasta los diseños curriculares, el perfil de los profesores, las cargas docentes y de investigación, las necesidades del mercado profesional, la vinculación de las universidades con la sociedad, la selección del alumnado, etcétera» ${ }^{5}$.

5 M. Carbonell, La enseñanza del Derecho, 1. a ed., México DF, Porrúa, 2004, pp. 72, 73 y 74 .

Foro, Nueva época, vol. 18, núm. 1 (2015): 125-168 
3. Improvisación docente y carencia de la profesionalización docente y, sobre todo, de investigadores de la cultura y ciencia jurídica.

4. Existe un porcentaje muy reducido de profesores de tiempo completo que se dediquen a la investigación jurídica.

5. La sobrepoblación escolar en la licenciatura en Derecho obstaculiza la puesta en práctica de alternativas metodológicas y técnicas activas del proceso enseñanza-aprendizaje del Derecho que permitan la aplicación de preseminarios y seminarios de investigación jurídica, así como de la observancia de las técnicas de investigación documental y de campo para hacer realidad la investigación jurídica realista.

6. En nuestro país, las instituciones que ofertan los estudios de Derecho, tanto de nivel licenciatura como de posgrado, con dificultad forman abogados postulantes y, por excepción, forman a los estudiosos de la cultura y ciencia jurídica.

7. Escasa producción en la investigación jurídica de frontera, a excepción de la que realiza el Instituto de Investigaciones Jurídicas de la UNAM y de los esfuerzos de algunas otras instituciones públicas generalmente que se encuentran en las siguientes entidades federativas: Instituto de Investigaciones Jurídicas de Xalapa (Veracruz), Instituto de Investigaciones Jurídico-Políticas de Puebla (Puebla), Instituto de Investigaciones Jurídicas del Estado de México y el Centro de Investigaciones Jurídico-Políticas y Estudios de Posgrado de Tlaxcala.

Lo antes citado genera los siguientes cuestionamientos que problematizan la presente investigación: el modelo de universidad napoleónica en México, ¿cómo obstaculiza la generación del conocimiento y la investigación jurídica de práctica científica? ¿Por qué motivo en las instituciones que ofertan los estudios de Derecho se informan contenidos desfasados de la realidad histórica concreta que actualmente vivimos? ¿Por qué en la actualidad hay demasiados abogados en nuestro país, pero con serias limitaciones en sus conocimientos, habilidades y competencias para ejercer de manera eficiente su profesión y, sobre todo, son escasos los científicos del Derecho? ¿Por qué motivo no hemos establecido y desarrollado en términos generales prácticas de investigación jurídica de naturaleza multidisciplinaria e interdisciplinaria? ¿Cómo integrar a los estudiosos del Derecho (estudiantes, docentes e investigadores) a la dinámica social, económica y política que se presenta en los nuevos escenarios que se dan a partir del tercer milenio? ¿Qué tanto y con qué frecuencia participamos los estu- 
diantes, docentes e investigadores de las ciencias jurídicas en la generación de alternativas para la solución de los problemas sociales, económicos, políticos e ideológicos que se presentan en el diario acontecer: regional, nacional e internacional? ¿Con qué frecuencia participan los estudiosos del Derecho (investigadores y demás profesionistas que se dedican a la procuración y administración de la justicia) para el efecto de hacer una sociedad más plural, abierta, tolerante y, sobre todo, corregir las asimetrías de una sociedad que padece grandes problemas en la desigualdad de los ingresos y de la distribución de la riqueza? ¿Con qué frecuencia se cuestiona la eficacia y eficiencia de las normas jurídicas que se encuentran en nuestra Carta Magna y demás disposiciones legales por parte de la comunidad de los estudiosos del Derecho en México? ¿Qué tanto hemos hecho los estudiosos del Derecho en México para salir del paradigma positivista decimonónico del Derecho? ¿Qué hacemos los estudiosos del Derecho en México para hacer realidad las cuestiones axiológicas y teleológicas del Derecho ( $v$. gr., justicia, equidad, igualdad, libertad, etc.)? ¿Por qué motivo no se generan en México con más frecuencia y aceptación las investigaciones jurídicas realistas o mixtas donde se utilicen técnicas de investigación más directas e inmediatas, como las de investigación de campo mediante la observación, entrevistas y encuestas, y que además estén vinculadas a la solución de los problemas sociales y económicos de los diferentes sectores de la sociedad mexicana (en concreto, a los problemas jurídicos que se plantean en los tribunales)?

Otra reflexión que considero de importancia es identificar el carácter y la trascendencia social que se genera en torno a la práctica de la investigación científica, tecnológica y humanista. Razón por la cual, cuando nos damos a la tarea de abordar los problemas que se originan y presentan con la investigación científica, no podemos soslayar el compromiso que se adquiere por parte de las instituciones en donde se realiza dicha práctica, así como con los investigadores y la sociedad.

En relación con este punto cabe citar lo expuesto por Antonio Hernández Gil, quien comenta lo siguiente: «La figura del científico ha dejado de ser una singularidad excepcional, ya que tenemos la asequibilidad de la ciencia para todos, que es una forma de socialización del saber y de sus resultados. De ahí que el trabajo individual, aun siendo insuprimible, no es suficiente» ${ }^{6}$.

${ }^{6}$ A. Hernández Gil, Problemas epistemológicos de la ciencia jurídica, 2. ${ }^{a}$ ed., Madrid, Civitas, 1976, p. 111. 
Asimismo, estamos de acuerdo en considerar a la investigación jurídica como un proceso cognoscitivo, teórico-práctico, complejo y dialéctico que va de lo abstracto a lo concreto y de lo deductivo a lo inductivo a través de una totalidad concreta. Dicho proceso nos permite de manera metodológica plantear problemas y expresar hipótesis dentro de un marco teórico de referencia en donde las fuentes formales, históricas y materiales del Derecho (legislación, jurisprudencia, doctrina, costumbre, expresiones culturales, económicas, sociológicas, políticas e ideológicas, etc.) proporcionan abundante información para el desarrollo de la investigación jurídica de práctica científica.

\section{ALGUNAS CONSIDERACIONES SOBRE LA DOCENCIA JURÍDICA EN LA NUEVA ESPAÑA}

El proceso de aculturación en la Nueva España resplandece con la aparición de la Real y Pontificia Universidad de México, ya que es la institución primigenia de educación superior que se establece en el nuevo mundo (continente americano), en donde por vez primera se ofertan los estudios de teología, escritura, cánones, leyes, artes, retórica y gramática, y, posteriormente, los estudios de medicina. Los títulos y grados académicos que se otorgan en la referida Universidad son los siguientes: bachiller, licenciado, maestro y doctor.

En relación con la fundación y desarrollo de la Real y Pontificia Universidad de México, Nicolás Rangel, retomando la investigación del bachiller De la Plaza y Jean acerca de la crónica de la insigne, real y pontificia Universidad, expresa lo siguiente:

«Soberano Señor de Cielo y Tierra, Cristo Nuestro Señor, verdadero Maestro, que en el Sacrosanto Madero de la Cruz como en Cátedra está vuestra Divina Majestad enseñando a los Doctos y Maestros Catedráticos, así a perdonar defectos, de los que no saben lo que se hace, como alumbrar a los que siguen el camino de las Ciencias; y vacilando, Señor, mi rudeza, a quién podría dirigir la obra de la Crónica de esta Insigne y Real Universidad de la Muy Noble y Leal Ciudad de México de la Nueva España, he tenido por muy asertado y dichoso empleo el dirigirla a Vuestra Sacrosanta Real Majestad [...] Vuestro humilde criado» ${ }^{7}$.

7 C. B. DE La Plaza y JeAn (bachiller, secretario y maestro de ceremonias de la dicha Real Universidad), Crónica de la Real y Pontificia Universidad de México, siglo XVII, 2 tt., 
En ninguno de los dilatados dominios de ultramar de la gloriosa España del siglo XVI se desarrolló más rápidamente la cultura de aquella nación como en la Nueva España. Todos los conocimientos científicos, literarios y artísticos que tanto distinguieron en esa centuria a la madre patria fueron transportados a nuestro país, en donde florecieron vigorosamente por encontrar un medio propio para ello.

Desde los primeros años que siguieron a la conquista se notó que tanto los criollos como los mestizos y los indios tenían notables disposiciones para ilustrarse y adquirir conocimientos aun de materias superiores. Debido a esto, el ayuntamiento de la ciudad de México, los prelados de las órdenes religiosas y, sobre todo, las reiteradas peticiones del primer virrey de Nueva España, don Antonio de Mendoza, que tanto se esforzó por la ilustración y el engrandecimiento de la colonia encomendada a su cuidado, consiguieron que el emperador semper augusto Carlos $\mathrm{V}$ expidiera la cédula de fundación de la Universidad ${ }^{8}$, que fue, sin duda alguna, la más importante del continente americano.

En los estatutos de la Universidad elaborados por el oidor Pedro Farfán en 1580, además de señalarse las cátedras de Cánones y Leyes, se indicaban las lecturas que en cada una de ellas habría de efectuar el catedrático. Las cátedras eran la de Prima de Cánones, en la cual, por no haber al presente otra de Decretales mayor ni menor, debería su titular explicar el referido Liber Decretalium distribuido en cinco años; la de Decreto, en la que se explicaría la obra de Graciano conforme al estatuto de la Universidad de Salamanca; la de Código, para dicha compilación justinianea también en cinco años, y la de Instituta, para la obra homónima en iguales cinco años?

En el proyecto de estatutos de la Universidad de México ordenados por el virrey Cerralvo en 1626 la situación de las cátedras de Cánones y Leyes prácticamente se mantuvo. En efecto, el título noveno del referido proyecto, que se ocupaba de lo que han de leer los catedráticos (sic) de Cánones de la real Universidad, disponía que, por no existir en Cáno-

479 y 300 pp., respectivamente. Se cita por la edición paleográfica, proemio, notas y apéndice del profesor N. Rangel, 1. ${ }^{\text {a }}$ ed., México DF, UNAM, 1931, pp. 3 y 4.

8 Apéndice, documentos I, citado por N. RangeL, «Proemio a la Crónica de la Real y Pontificia Universidad De México escrita por Cristóbal Bernardo de la Plaza y Jean», op. cit., p. V.

9 Consultar los estatutos de esta Real Universidad elaborados por el doctor Pedro Farfán («Tit. V. De lo que han de leer los catedráticos de Cánones y Leyes») en J. JimÉNEz RuEDA, Las Constituciones de la antigua universidad, México, Facultad de Filosofía y Letras, 1951, citado por J. Barrientos Grandon, La cultura jurídica en la Nueva España, 1. ${ }^{a}$ ed., México DF, Instituto de Investigaciones Jurídicas de la UNAM, 1993, p. 124. 
nes más que un catedrático de Prima, debería leer las Decretales de Gregorio IX en cinco años, y el catedrático de Decreto, el referido texto en iguales cinco años. Además, en el título décimo se agregaba que el catedrático de Sexto leería alternativamente dos años de Título y uno de Clementinas, y el libro y títulos tanto del Sexto como de Clementinas.

De su lado, en Leyes, en cuatro años, el catedrático de Prima leería, alternando, el primero el Digesto Biejo, el segundo el Esforzado, el tercero el Digesto Nuevo y en el cuarto debería ocuparse en leer los títulos del Digesto: De Petitione hereditatis (D. 5.3), Del Interdicto quod vi aut clan (D. 4.34) y De Verborum significalione (D. 50.16). El de Código leería en cinco años el referido texto justinaneo y el de Instituta ocuparía otros tantos para la obra homónima ${ }^{10}$.

Por su parte, en las Constituciones formadas por Juan de Palafox en 1645 y aprobadas por el monarca en 1649 , que con diversas reformas se aplicaron durante toda la época indiana, las cátedras de Cánones eran las de Prima, para el Liber Decretalium; Decreto y Sagrados Concilios, para la obra de Graciano y cánones conciliares posteriores; Vísperas, para el Liber Sextus, y Clementinas, para la compilación homónima o Liber septimus. Las de Leyes eran las de Prima, para las tres partes del Digesto; Vísperas, para el Código, e Instituta, para las Instituciones de Justiniano ${ }^{11}$.

En lo tocante al método de los estudios jurídicos y a las obras empleadas en ellos, no son muy abundantes los datos; sin embargo, para los primeros años de la Universidad se conservan las preciosas noticias que ofrece su primer catedrático de retórica, Francisco Cervantes de Salazar (c. 1514-1575), en uno de sus tres diálogos latinos titulado Academia Mexicana, escrito en 1554, un año después de instalada la Universidad ${ }^{12}$.

De las cátedras de Cánones refería lo que sigue:

«Para leer Cánones, de que es catedrático de Prima, sube a la cátedra el doctor Morones, a quien tanto debe la jurisprudencia. Sus discípulos, que son muchos, le oyen con gusto por su claridad. Muchos le siguen. Y

${ }^{10}$ Consultar los estatutos hechos en la Real Universidad de México en E. González González, Proyecto de estatutos ordenados por el Virrey Cerralvo (1626), México, Cesu, 1991, citados por J. BarRientos GRANDON, La cultura jurídica en la Nueva España, op. cit., p. 125.

${ }^{11}$ Constituciones de la Real y Pontificia Universidad de México citadas por J. BARRIENtos Grandon, La cultura jurídica en la Nueva España, op. cit., p. 125.

${ }_{12}$ Publicado en F. Cervantes de Salazar, Comentaria in Ludovici Vives Exercitationeslinguae latinae, 1554, citado por J. BARRIENTOS GRANDON, La cultura jurídica en la Nueva España, op. cit., p. 125. 
con razón. De las diez a las once, y en la misma cátedra, el doctor Arévalo Sedeño explica y declara los Decretos Pontificios con tal exactitud y perfección que los más doctos en Derecho nada encuentran digno de censura, sino mucho que admirar, como si fuesen palabras de un oráculo. Es copioso en los argumentos estériles, conciso en los abundantes, pronto en las citas, sutil en las deducciones. Presenta sofismas y los deshace, nada ignora de cuanto hay más oscuro y elevado en Derecho, y por decirlo de una vez, es el único que puede hacer jurisconsultos a sus discípulos» ${ }^{13}$.

La descripción que hacía de las explicaciones de la clase del doctor Arévalo Sedeño no era más que un vivo retrato del método escolástico propio del mos italicus, que largo tiempo predominó en la enseñanza jurídica, conforme al cual el catedrático, tras leer el texto pertinente a su facultad, ponía los casos o dificultades que planteaba y, recurriendo a las glosas y comentarios, los resolvía en una solución magisterial. Por ello se alababa a este doctor, pues era pronto en las citas y sutil en las deducciones.

Y muy conforme con esto, al describir el trabajo común de la Universidad explicaba: «Debo decirte que en los días no feriados hay continuas lecciones y explicaciones de autores de las siete a las once de la mañana y de dos a seis de la tarde. Algunos profesores dan cátedra dos veces al día y los demás una sola».

De las cátedras de Leyes sólo se refería a la de Instituta, dictada por el conocido autor del arte de los contratos Bartolomé Frías de Albornoz (1521-157?), al señalar que: «De las cuatro a las cinco da cátedra de Instituta, con bastante acierto, el doctor Frías, maestro también en Artes, peritísimo en griego y latín, pero lo más admirable es que aún no ha cumplido treinta y cuatro años».

La constitución 19 del título $\mathrm{V}$ de las formadas por el oidor Pedro Farfán en 1580 confirmaba el método de estudios fundado en la lectura del texto y de la glosa, pues disponía que quienes quisieran explicar en Cánones y Leyes extraordinariamente podían hacerlo con tal que leyeran solamente el texto y la glosa:

«Si hubiere pretendientes que quieran leer extraordinariamente podrán leer otras materias lo que mejor les pareciere, conque no se encuentren con las materias que los catedráticos han de leer en aquel año, teniendo en todo en cuenta, así en las lecciones de Cánones como de Leyes, de pasar lo más

\footnotetext{
13 Ibid.
} 
que pudieren, leyendo solamente el texto y la glossa, en lo cual se encarga al rector la consciencia para que en las visitas que hiciere de las cátedras, haga averiguaciones y que no se detengan los catedráticos mucho tiempo en los textos, aunque sean famosos, sino que respecto de las pocas cátedras se puedan pasar y leer todas las materias susodichas» ${ }^{14}$.

Había también cierto tipo de trabajos universitarios que tenían que hacerse en manuscritos, tales como las tesis para la obtención de grados y las relecciones presentadas en los concursos de oposición a cátedras. Excepcionalmente se imprimían algunos de estos trabajos, pero la mayoría permanecían en su forma original.

La forma de impartir las clases en la Real y Pontificia Universidad fomentaba el uso de manuscritos. Según las Constituciones de Farfán ${ }^{15}$, la hora de clase se dividía en dos partes: en una el catedrático dictaba algún texto; en la otra lo explicaba aduciendo argumentos propios y de otros autores. Los estudiantes, por consiguiente, debían estudiar sobre sus propios apuntes y el maestro debía tener por escrito sus comentarios a los textos. Es significativo que en la Nueva España no se imprimieron libros destinados a la enseñanza jurídica sino hasta fines del siglo XVIII, cuando se publican las Institutiones sive Epitome Iuris civilis, carmine latino, in gracia tyronum, qui jurisprudentiae studio vacant, opus elaboratum, de José Bernárdez de Rivera (México, 1733), y las Elucidationes o explicaciones de las Instituciones de Justiniano hechas por el jurista español Sebastián Magro y completadas por nuestro Ventura Beleña (México, 1787) ${ }^{16}$.

Al margen de esta constitución se resumía su contenido en los términos siguientes: «Lean sólo textos y glosa y se encarga a los rectores la conciencia».

En el proyecto de estatutos ordenados por el virrey Cerralvo en 1626, en su título 17, «De cómo an de leer los lectores y a qué ora, y cómo an de oir los oyentes», traían una primera y muy interesante constitución tocan-

${ }^{14}$ J. BarRientos Grandon, La cultura jurídica en la Nueva España, op. cit., pp. 126 y 127.

15 Estas Constituciones de la Real y Pontificia Universidad de Nueva España se conservan en C. B. DE la Plaza y Jean, en N. Rangel (ed.), Crónica de la Real y Pontificia Universidad de México, op. cit. Han sido reproducidas también por A. M. ${ }^{a}$ Carreño, La Real y Pontificia Universidad de México, 1535-1865, México, UNAM, 1961, pp. 304 y ss., y por J. JiméNEZ RuEDA, Las Constituciones de la antigua universidad, op. cit.

${ }^{16} \mathrm{~J}$. Adame Goddard, «Los manuscritos jurídicos latinos de la Biblioteca Nacional», en Memoria del IV Congreso de Historia del Derecho Mexicano, Serie C, Estudios Históricos, núm. 25, 1. a ed., México DF, Instituto de Investigaciones Jurídicas-UNAM, 1988, pp. 17 y 19 . 
te al modo de leer en la facultad de Cánones y Leyes, que venía a completar las respectivas del estatuto de Farfán de 1580:

«Yten, por quanto en el estatuto del título que trata del modo de leer en la facultad de cánones y leies avía quedado muçha confusión, y por esta razones en las visitas y proviçiones se a alterado diversas veses el uso del dicho estatuto, visto todo y conferido, parese ser mui conveniente y necesario apartar el tiempo de declarar y el tiempo de escrevir.

Por tanto, estatuimos y hordenamos que de aquí adelante, todos los catedráticos y lectores de Cánones y Leyes y teulogía sean obligados a gastar la mitad de la ora en dictary la otra mitad en explicar biba bocis e in fluxu orationis "De viva voz en palabras fluidas" ${ }^{17}$, insistiendo en todo ese tiempo dicho de la media ora solamente en el verdadero entendimiento del texto y dificultad de las glosas Abad y Bartolo, sacando en limpio la verdadera y común doctrina, sin derramarse a materias estrañas e impertinentes; y que en el tiempo del explicar no escriva ningún oyente, ni el catedrático o lector la conçienta, para que pueda leer con grande aplauso y atençión. Y que la otra media ora de el tiempo pueda el catedrático recoger de la disputa una breve teórica en la cual rresuelta quál es la verdadera y común opinión, y el prinçipal texto y fundamento de ella, para que el oyente pueda aser memoria y cultivar el ynjenio y entendimiento. Y que esto se guarde inviolablemente, leyendo siempre en latín, si no fuere declarado alguna dificultad o poniendo exenplo o rrefiriendo alguna lei del rreino, todo lo qual guarden y cumplan y no lo puedan quebrantar, so pena de sinquenta pesos por la primera ves, y por la segunda de çient pesos, aplicados para gastos de la capilla de la real universidad; además de que en conçiencia no puedan hazer suyos los fructos y emolumentos de la cátedra; y encargamos la conçiençia al rrectorlo execute con mucha diligençia y rrigor» ${ }^{18}$.

El primer comentario que merece esta disposición toca al método de explicar en las facultades de Cánones y Leyes, que era del más tradicional mos italicus («costumbre o modo itálico») ${ }^{19}$, pues el catedrático debía ocupar la primera mitad de la clase en dictar a los escolares el texto objeto de estudio y, una vez que éstos lo hubieran copiado, debía destinar el resto de la lección a explicar el texto, declarando y disputando las cuestiones que ofrecían tanto aquél como los comentarios de Nicolás Tudeschis en Cáno-

17 Traducción realizada por Nicolás Dávila Peralta, profesor y periodista de comunicación social de la BUAP, Puebla, Pue, 14 de diciembre del 2000.

18 E. González, Proyecto de estatutos ordenados por el Virrey Cerralvo (1626), citado por J. Barrientos Grandon, La cultura jurídica en la Nueva España, op. cit., pp. 127 y 128.

19 Traducción del latín al español realizada por Nicolás Dávila Peralta. 
nes, y de Bartolo de Sassoferrato en Leyes. Fruto de este ejercicio debía ser extraída la verdadera communis opinio («opinión comun») ${ }^{20}$, pues, tras la disputa, el catedrático podía en una breve exposición teórica resolver cuestiones y declarar la referida opinión común.

Método éste que no correspondía más que a la antigua divisa de Cino de Pistoia (1270-c. 1336) tocante al trabajo de los textos, respecto del cual había declarado: «circa cuitus lecturam tenebo bunc ordinem: quia primo dividam, secundum ponam, tertio colligan, quarto opponam, quinto quaeram ${ }^{21}$ [«en torno de la lectura (en el sentido de clase, lección) tengo este orden: porque primero divida; segundo, ponga; tercero, relacione; cuarto, oponga; quinto, investigue»] ${ }^{22}$.

Un segundo comentario toca la obligación inviolable del catedrático de leer su facultad en latín, a menos que tratare de declarar grande dificultad de poner un ejemplo o referir alguna lei del rreino, es decir, los catedráticos de Cánones y Leyes podían explicar las leyes reales a propósito de la lectura del Derecho canónico y civil, e incluso más podían hacerlo en lengua vulgar.

Para el estudio de la enseñanza durante la segunda mitad del siglo XVII en la Universidad de México se cuenta con la del maestrescuela y catedrático de Decreto y Sagrados Concilios de la Universidad de México, Miguel de Ibarra, que publicó en 1674 las lecciones que había leído en su cátedra de Decreto durante el curso de veinte años bajo el título de Annuae relectiones ad Canonicae Iuris explicationes in duas partes divisae. In quibus capita Magistri Gratiani Decreti Scholastica methodo expediuntur, E sapientissimorum Doctorum turiores doctrinae afferuntur. Utriusque iuris incumbentis valde utiles. Perlectae secundum Statutorum ordinem in Regali Mexicana Academia ${ }^{23}$ («En torno a las explicaciones del Derecho canónico las lecciones son divididas anualmente en dos partes, ordenadas según el principio del método escolástico: del Decreto del Maestro Graciano y se hacen saber las doctrinas de los doctores sapientísimos. Ambos sumamente útiles para el apoyo del derecho, leídas completamente conforme al orden de los Estatutos de la Real Academia Mexicana») ${ }^{24}$.

20 Ibid.

21 F. Calaos, Medio Evo del Diritto (1954), citado por J. Adame Goddard, Memoria del IV Congreso de Historia del Derecho Mexicano, op. cit., p. 128.

22 Traducción del latín al español realizada por Nicolás Dávila Peralta.

${ }_{23}$ M. DE IBARRA, Annuae relectiones ad Canonicae Iuris explicationes, citado por J. BARRIENTOS GRANDON, La cultura jurídica en la Nueva España, op. cit., p. 128.

24 Traducción del latín al español realizada por Nicolás Dávila Peralta. 
Una rápida lectura de este texto nos muestra una obra claramente escolástica, que por lo demás así lo declara su propio título, compuesta conforme al método tradicional del mos italicum, donde el maestro ponía el caso del texto, luego dividía y distinguía, concluía, planteaba las objeciones a su conclusión y, finalmente, las resolvía valiéndose para ello de la autoridad de la propia Glossa del Decreto y de autores como el Abad Panormitano, amén de citas bíblicas.

Por ejemplo, en la Relectio super distinctio I. Ex Decretum Gratiani, De iure humanae E Divinae («Lección sobre la distinción I. Sobre el Decreto de Graciano, de derecho humano y divino») ${ }^{25}$ comenzaba por exponer el casus:

«Haec distinctio dividitur in duas partes, ut in glossa facile est videre. Casus autem sic figuratur. Duo sunt instrumenta, per quae bumanum genus regitur, E gobernatur, scilicet ius naturale, E consuetudo, sive mos. Ius naturale in lege, E Evangelio continetur, qua quisque iubetur alii facere, quod sibi vult fieri, E probibetur alii inferre quod sibi fieri habetur Mathei» [《Esta distinción se divide en dos partes, como es fácil ver en la glosa, así como también en el caso descrito. Son dos los instrumentos por los cuales se rige y es gobernado el género humano y es gobernado: el derecho natural y el consuetudinario, o por mejor decir, la costumbre. El derecho natural está contenido en la ley y el Evangelio, de donde uno ordena a la otra hacer lo que en sí mismo quiere realizar, y se infiere que también prohíbe uno a la otra, como se indica en (el Evangelio) de Mateo»] ${ }^{26}$.

Luego decía que para exponer con más claro método esta materia era necesario distinguir, y lo hacía en cuatro partes:

«Et quod clariori supponamus, necesaro praesupponedum existimo divisionem banc nos redistinctionis, in quatuor partes fieri debere. In I nostrae distinctionis parte noster Gratianus ostendit, bumanum genus duobus regi, E gubernari, iuribus scilicet, \& consuetudine. In II ponit aliam divisionem iuris, scilicet in ius scriptum, $\mathcal{E}$ in uis non scriptum: sive hoc memoriae commendatum sit, sive consuetudine introductum. In tertia ponit aliam divisionem iuris, in triplex partitam membrum: videlicet in ius naturale, ius civile, $\mathcal{E}$ ius gentium. In IV species iuris civilis prosequitur» ${ }^{27}$ [《Y lo que claramente suponemos nosotros es que juzgo necesario rehacer esta distinción en
25 Ibid.
${ }^{26}$ Ibid.
27 J. Barrientos Grandon, La cultura jurídica en la Nueva España, op. cit., p. 130. 
cuatro partes. En I, nuestro Graciano muestra parte de nuestra distinción: que el género humano se rige y gobierna con el derecho y la costumbre. En II pone otra división al derecho, a saber: en derecho escrito y derecho no escrito, o por mejor decir, aquello que confiadamente se introduce por la costumbre. En tercero, pone otra división al derecho en una triple parte, en decir: derecho natural, derecho civil y derecho de gentes. En IV, prosigue el estudio del derecho civil» $]^{28}$.

Inmediatamente se preocupaba por explicar la primera parte, no sin antes volver a distinguir sobre la base de cuatro quaestiones:

Quod autem ad primam nostram divisionis partem attinet, videlicet bumanum genus duobus regi E gubernari, scire oportet quid iuris nomine comprehendatur [ LLo cual, por tanto, pertenece a la primera parte la división, pues es evidente que el género humano se debe regir y gobernar. Conviene ahora saber con qué nombre del derecho es comprendido»] ${ }^{29}$.

Quod sit etiam ius naturale, quae dicatur divinum. Quae sit eius praecep$t a$, E in quo consistan [«Qué sea el derecho natural, que es llamado divino, qué sean sus preceptos y en qué consisten»] ${ }^{30}$.

Ahora bien, con el propósito de ahondar más en la forma en qué y cómo se enseñaba en las facultades de Cánones y Leyes cabe hacer mención de lo siguiente.

El título 17 es particularmente interesante, pues constituye una breve didáctica de la Universidad, ya que en él se determina cómo han de leer los lectores y a qué hora y cómo han de oír los oyentes. Conocemos cuál era el horario de las cátedras, cómo se distribuía el tiempo de la explicación y cómo se exigía de los catedráticos no sólo la asistencia durante todo el periodo lectivo, sino también la puntualidad absoluta, pues se defraudaba a los estudiantes y a la Universidad al dar menos tiempo que el obligado. Explica que la primera mitad de la hora de cátedra debe ser empleada en declarar «la doctrina» y la segunda en escribir las conclusiones. Dice textualmente: «Los catedráticos y los lectores de Cánones, Leyes y Teología sean obligados a gastar la mitad de la hora en dictar y la otra hora en explicar declarando y disputando de viva voz, insistiendo en este tiempo dicho de la media hora solamente en el verdadero entendimiento del texto y dificultad de las glosas [...], sacando en limpio la verdadera y común doctri-

28 Traducción del latín al español realizada por Nicolás Dávila Peralta.

${ }^{29}$ Ibid.

30 Ibid. 
na sin derramarse a materias extrañas e impertinentes y que en el tiempo de explicar no escriba ningún oyente ni el catedrático o lector lo consienta para que pueda leer con grande aplauso y atención y que la otra media hora del tiempo pueda el catedrático recoger la disputa en una breve teoría en la cual resuelva cuál es la verdadera y común opinión y el principal texto y fundamento de ella para que el oyente pueda hacer memoria y cultivar el ingenio y entendimiento y que esto se guarde inviolablemente leyendo siempre en latín si no fuere declarado alguna gran dificultad o poniendo ejemplo o refiriendo alguna ley del Reino, todo lo cual guarden y cumplan y no lo puedan quebrantar so pena de cincuenta pesos por la primera vez y por la segunda doscientos aplicados para gastos de la capilla de la Real Universidad, además de que no puedan hacer suyos los fructos y emolumentos de la cátedra y encargamos la conciencia del rector y los ejecute con mucha diligencia y rigor» (folios 35, 36 y 37 del expediente citado) ${ }^{31}$.

Se practicaba ya cierta libertad de docencia, pues podrán «salir a leer extraordinariamente otras personas» siempre que sean temas distintos a los que se enseñan en otras cátedras y que se den a hora distinta de las regulares y previo permiso del rector.

Dentro de la Universidad los maestros no deben tener estudio privado para enseñar particularmente a los estudiantes. Terminantemente se obliga a los maestros a que «lean una hora toda la cual sea entera sin hacer falta en ella» $\mathrm{y}$ «a los que falten el bedel tenga cuidado en multallos y el rector en las visitas que hiciese lo mande así hallando a cualquier catedrático que falte en leer la dicha hora y particularmente se les encarga a los catedráticos y lectores las conciencias ya que no es justo que defraude en el tiempo a la Universidad y a los estudiantes» (fol. 39 vta.).

El horario fijado para las cátedras era el siguiente: Prima de Cánones de las 7 a las 8 de la mañana, Prima de Leyes de las 8 a las 9, y Clementinas de 10 a 11. Por la tarde, Sexto de 2 a 3, Código de 3 a 4 e Instituta de 4 a 5.

Los profesores deberían emplear una hora íntegra en la exposición de sus temas; en consecuencia, parece que no se acostumbraba «tomar la clase» a los estudiantes; solamente en los exámenes de fin de año se podían estimar los conocimientos adquiridos por éstos.

Había, sin embargo, un acto cada año para aquilatar aprovechamientos en el salón general de la Universidad. Se organizaban tres disputas en las que participaban cuatro estudiantes escogidos por sus maestros y algu-

31 Consultar Estatutos del doctor Pedro Farfán, citado por J. Jiménez RuedA, Las Constituciones de la antigua universidad, op. cit., pp. 41 y 42. 
nos doctores en leyes. Los estudiantes exponían puntos y razonamientos previamente preparados por ellos y los doctores les rebatían. A cada estudiante se le daba una propina de cuatro reales y un peso al doctor que presidía la disputa ${ }^{32}$.

Hubo durante la época colonial, en las facultades de Cánones y Leyes, profesores mediocres y otros brillantísimos, como en todas las universidades y en todos los tiempos.

\section{LA DOCENCIA JURÍDICA EN EL MÉXICO INDEPENDIENTE}

Las colonias españolas de América contaban con fuertes elementos para resistir, pues aunque el grito de libertad había despertado las pasiones aletargadas por trescientos años de esclavitud, los excesos de la demagogia francesa, exagerados hasta el último extremo, habían también robustecido en unos las preocupaciones y debilitado en otros el entusiasmo. En suma, México no era todavía el hombre formado que en 1821 debía emanciparse para siempre de sus tutores; tenía que pasar por la revolución para conquistar la independencia; tenía que regar con lágrimas el sendero del infortunio para gustar la copa de la ventura ${ }^{33}$.

Durante el siglo XIX nuestro país se vio envuelto en un ambiente controvertido y convulsionado. Ahora bien, los sucesos históricos del referido siglo no surgieron de manera espontánea, sino que fueron producto de un largo y sinuoso proceso histórico.

Así pues, a finales del siglo XVIII e inicios del XIX nuestro país recibió la influencia de los teóricos de la Ilustración. Formaron parte de ella D'Alambert, Diderot, La Mettrie, Voltaire, Rousseau, Holbach y muchos otros.

Así, como la independencia de las trece colonias de América del Norte de fecha 4 de julio de 1776, igualmente el impacto de la Revolución Francesa del 14 de julio de 1789 .

Por otra parte cabe resaltar que, en el mes de marzo de 1808, las tropas de Napoleón entraban incontenibles en la Península Ibérica. La cabeza del imperio más grande de la cristiandad parecía haber renuncia-

32 Ibid., p. 43.

33 J. M. ${ }^{a}$ Lafragua, Arenga cívica pronunciada el día 27 de septiembre de 1843 en la alameda de México, Memoria de la gloriosa consumación de la independencia de México, México, Imprenta de Torres, 1843 , pp. 8 y 9. 
do a su dignidad y a su orgullo; el pueblo español, abandonado por sus reyes, asume la iniciativa; en las calles de Madrid inicia la resistencia contra los invasores. Es así como España entra en un proceso modernizado de su vida política a través de la Constitución de Cádiz de fecha 19 de marzo de 1812.

Al respecto, José Luis Soberanes Fernández nos dice:

«La Ilustración y sus postulados fue la gran fuerza exógena que movió nuestra guerra de independencia, pero no debemos olvidar una fuerza endógena fundamental: la toma de conciencia nacionalista de los criollos novohispanos, sinergizados por una evidente actitud contraria a los criollos en la provisión de empleos y funciones para Indias por parte de las autoridades peninsulares» ${ }^{34}$.

Ahora bien, el antagonismo entre criollos y gachupines nunca corrió con suerte entre las familias privilegiadas. Más bien sería creación de los letrados de las clases medias, que se harán los voceros de los intereses americanos. Esa distinción racial funcionará entonces como una racionalización de antagonismos más profundos. Como sucede a menudo, los conceptos de raza y nacionalidad servirán para encubrir y dramatizar diferencias económicas y sociales ${ }^{35}$.

El relativo crecimiento del mercado interno a contrapelo de las restricciones, el incipiente desarrollo urbano industrial y el alimento de la burocracia propiciaron cierto crecimiento de los sectores intermedios: pequeños comerciantes y administradores, escribanos, abogados. Además, el personal eclesiástico era muy numeroso. La gran mayoría carecía de prebendas y de fortuna personal, no estaba integrado económicamente a la oligarquía, sino que pertenecía al sector intermedio de los servicios. El alto clero estaba constituido por sacerdotes que ocupaban las dignidades eclesiásticas o los puestos importantes en la administración de fincas, capellanías y obras pías de la Iglesia.

Lamentablemente, los indios y castas, base de la pirámide social de Nueva España, sólo compartían la miseria. Además, eran considerados en estado perpetuo de minoría de edad ${ }^{36}$.

34 J. L. Soberanes Fernández, Historia del sistema jurídico mexicano, 1. a ed., México DF, Instituto de Investigaciones Jurídicas de la UNAM, 1990, p. 50.

${ }^{35}$ L. Villoro, La revolución de independencia. Historia General de México, t. 2, 2. ${ }^{a}$ ed., México DF, El Colegio de México, 1977, pp. 312 y 313.

${ }^{36}$ Ibid., p. 314. 
Habida cuenta lo antes expresado se colige, sin lugar a dudas, que los criollos de la Nueva España desempeñaron un papel trascendental para la transformación del México independiente del siglo XIX.

La guerra de independencia al iniciarse tuvo el cariz de un movimiento popular de indios y mestizos en la famosa proclamación del emocional sacerdote Hidalgo el 15 de septiembre de 1810. La situación era sumamente confusa, pero después de los éxitos iniciales de Hidalgo pronto se hizo evidente que a la larga no triunfaría; los criollos querían la independencia, pero no bajo el régimen de fanáticos visionarios, ni gracias a una guerra de castas.

Así, muchos de los que habían estado en contra de los peninsulares en los diversos movimientos que podemos observar desde 1808 ahora colaboraron con los peninsulares contra los insurgentes (para luego juntarse con Iturbide, en 1821, con el fin de obtener una independencia en que ni los ideales populares de Hidalgo y Morelos, ni tampoco el espíritu liberal de la Constitución de Cádiz pudiera perturbar su modo de vivir) ${ }^{37}$. El plan de Iguala logró unificar a toda la oligarquía criolla. El proyecto de independencia aparecía, en efecto, claramente ligado a otras dos garantías que tomaba muy a pecho el mantenimiento de la religión y del orden social en la unión de todas las clases. Uno tras otro todos los cuerpos del ejército se unen a Iturbide.

Después de más de diez años de lucha armada se logra la consumación de la independencia de México. El 27 de septiembre de 1821, Agustín de Iturbide al frente del ejército de las tres garantías (religión, unión e independencia) entra triunfante a la ciudad de México ${ }^{38}$. Empero, esto no significa que los antagonismos dejen de presentarse. Ahora aparecen en escena dos posiciones contrarias: por un lado, la de los conservadores y, por el otro, la de los liberales.

Los conservadores representaban los intereses más reaccionarios, partidarios de gobiernos de corte centralista. Además, pretendían conservar las relaciones sociales y fuerzas productivas del sistema feudal. También se inclinaban por establecer como forma de gobierno la monarquía hasta llegar al extremo de recibir con beneplácito la invasión extranjera y el establecimiento del imperio de Maximiliano de Habsburgo. Asimismo, se preocupaban por seguir conservando una educación dogmática.

37 G. Floris Margadant, Introducción a la Historia del Derecho Mexicano, 11. a ed., México DF, Esfinge, 1994, p. 112.

${ }^{38}$ Cfr. L. Villoro, La revolución de independencia..., op. cit., p. 346. 
Al respecto, José Luis Soberanes Fernández considera lo siguiente:

«La Iglesia durante la época colonial conservó una serie de exenciones, privilegios y fueros heredados de la Edad Media, concesiones que se oponían al principio de igualdad de todos los hombres frente a la ley. Por otro lado, la Iglesia y sus instituciones (órdenes, cofradías, etcétera) fueron reuniendo una serie de bienes que le llegaban mayormente por vía hereditaria y que se iban conservando para sufragar las obras sociales a ellas confiadas, como por ejemplo los hospitales, asilos, escuelas, atención a mujeres solas y mendigos, los cuales además, por ese hecho, salían del comercio, se decía que pasaban a manos muertas, se «amortizaban»; por ello las instituciones eclesiásticas daban la impresión de ser inmensamente ricas. Finalmente diremos que esas mismas instituciones tenían encomendadas la educación de la niñez y de la juventud, con la cual se ha querido ver a la Iglesia como una gran maquinaria de ideologización política. La iglesia también regulaba y administraba lo relacionado con el estado civil de las personas como nacimientos, matrimonios, defunciones y parte del derecho de familia. En contrapartida tenemos que señalar que la Iglesia, sus autoridades y su clero estaban, en esa época colonial, absolutamente controlados por el Estado a través del Regio Patronato Indiano» ${ }^{39}$.

Por su parte, los liberales representaban a la posición más progresista de la sociedad mexicana. Éstos se inclinaban por gobiernos republicanos y federalistas. Igualmente se caracterizaron por apoyar el establecimiento y desarrollo de las relaciones sociales y fuerzas productivas del sistema capitalista. Además, lucharon por una educación laica, positivista y popular.

En definitiva, buena parte de las ideas que generalmente aparecen vinculadas al tema liberal circularon durante el periodo preindependentista como aroma ideológico justificatorio de la necesidad de romper el vínculo colonial.

Así pues, los liberales plantearon someter a la Iglesia, quitarle privilegios y exenciones, lo mismo que los bienes que no fueran estrictamente indispensables para el desarrollo de su ministerio, así como la educación de la niñez y de la juventud, el control y registro de actos del estado civil; por último, no reconocer a ninguna religión como oficial. En síntesis, reducir las actividades de la Iglesia a las cuatro paredes del templo ${ }^{40}$.

En la década de los cuarenta del siglo XIX surge una pléyade de liberales mexicanos. Entre otros cabe mencionar a Miguel Ramos Arizpe, Juan

\footnotetext{
39 J. L. Soberanes Fernández, Historia del sistema jurídico mexicano, op. cit., pp. 62 y 63.

40 Ibid., p. 63.
} 
Álvarez, Ignacio Comonfort, José María Lafragua, Mariano Riva Palacio, Guillermo Prieto, Melchor Ocampo, Benito Juárez, Sebastián Lerdo de Tejada, etcétera.

Por lo que respecta a José María Lafragua, cabe hacer mención de una reflexión de Ernesto de la Torre Villar, quien expresa lo siguiente:

«Lafragua no ha sido apreciado en su justo valor. Cada una de las actividades en provecho de México bastaría para que se le considerara como uno de los hombres más eminentes de la República; sin embargo, por no haber pertenecido a ningún grupo extremista se le desconsidera, pese a que su labor fue más patriótica, positiva y valiosa que la de muchos de sus contemporáneos. En política mantuvo, con su amplio criterio liberal, una posición firme y de gran rectitud, sin manipuleos de ninguna naturaleza» ${ }^{41}$.

Igualmente, Lafragua pensó que era indispensable luchar en beneficio de México en todos los frentes y que el de la cultura requería apoyo. Por ello consagró su vida a la República, a fomentar los establecimientos de cultura existentes y crear los que el país necesitaba dotándolos de cuantos recursos materiales estaban a su alcance. El estímulo y ayuda que dio a numerosas instituciones le acreditan como uno de los forjadores de la cultura nacional ${ }^{42}$.

«Como resultado del positivismo jurídico del siglo pasado (XIX) y principios del presente (xx) se pensó que el estudioso del Derecho tenía que almacenar en su memoria el contenido de todas las leyes en vigor para después aplicarlas al caso concreto, en un increíble ejercicio hermeneútico; de ahí que hasta hace poco tiempo se destacara el carácter memorístico de la carrera de Derecho, dado que el Derecho no está formado únicamente por leyes vigentes, sino por otras muchas cosas más. Frente a esa manera de contemplar el Derecho y al ver como recientemente el legislador ha sacado una ingente producción legislativa, resultaría absolutamente imposible registrar en la memoria tal cúmulo de disposiciones, de ahí que nuevamente se esté cayendo en la cuenta que el verdadero jurista no es el que "sabe leyes, sino el capacitado para interpretar el Derecho", es decir, el que tiene criterio jurídico; por ello, la función de las facultades y escuelas de Derecho

${ }^{41}$ «Introducción» a la obra de M. ${ }^{a}$ L. HeRnÁndeZ y F. DuRÁn, José María Lafragua. Obra bibliográfica, bemerográfica y documental, México DF, Archivo Histórico Diplomático de México, Secretaría de Relaciones Exteriores, 1986, p. 15.

${ }^{42}$ R. SÁnchez VÁzQuez, «Vida y obra de José María Lafragua y la Biblioteca José María Lafragua de Puebla», en Anuario Mexicano de Historia del Derecho, t. VII, México DF, Instituto de Investigaciones Jurídicas de la UNAM, 1995, pp. 163-167. 
se contempla ya no tanto en dar información, sino dar formación a los que pretenden ser juristas» ${ }^{43}$.

«La explicación oral, tal como suele hacerse en nuestras facultades jurídicas, no interesa ni puede interesar a los estudiantes; cuando es una elevada exposición de principios teóricos hecha en forma rigurosamente científica, tan sólo unos pocos están en condiciones de entenderla, al paso que la masa estudiantil asiste a ella extraña y aburrida como el que oye recitar un discurso en lengua extranjera; la explicación oral en la que el profesor habla para todos y para nadie, en forma para algunos elevada y para otros demasiado modesta, impide al docente dirigirse a cada discípulo en el lenguaje más apropiado a su madurez intelectual».

Consecuentemente, la enseñanza tradicional del Derecho debe ser desterrada de la escuela por la absoluta pasividad intelectual a que condena a los estudiantes, obligados a aceptar, sin posibilidad de crítica ni de refutación, los resultados del pensamiento ajeno. Así, la lección, en vez de una saludable gimnasia del espíritu, se ha convertido en una cómoda escuela de holgazanería, y los alumnos, incluso los más estudiosos, después intentado en vano las primeras veces reaccionar contra la tiranía de unos métodos que enseñan a pensar con la cabeza de los demás, se dejan poco a poco vencer por la seducción de un sistema tan poco fatigoso para ellos, y si, no obstante, continúan frecuentando materialmente las clases, permanecen espiritualmente ausentes de ellas, sumidos, mientras el profesor habla, en una especie de placidísimo sopor mental que, a menudo, en las tardes calurosas, se convierte en dulce sueño físico ${ }^{44}$.

También es oportuno resaltar que la exposición oral del profesor en un ambiente masificado es estéril. En virtud de que es muy difícil mantener la atención de los alumnos por periodos que excedan de los diez minutos después de haber iniciado la clase.

Los profesores acuden de manera mecánica a la exposición oral como único recurso didáctico, entre otras razones, porque desempeñan la actividad docente en forma improvisada. Toda vez que consideran a la actividad de dar clases como un deporte de mnemotécnica de recitar ante los alumnos algunos párrafos de un libro o algunas disposiciones legales de manera asistemática, en el mejor de los casos, ya que, en ocasiones, dicha exposición verbalística nada tiene que ver con la disciplina que se les ha asignado.

43 J. L. Soberanes Fernández, Historia del sistema jurídico mexicano, op. cit., p. 10.

44 Cfr. P. Calamandrei, Demasiados abogados, trad. de J. R. Xiraux, 1926, pp. 159-160, citado por R. DE PINA, Pedagogía universitaria, México DF, Ediciones Botas, 1960, pp. 33-34. 
Ahora bien, ¿en qué consiste doctrinariamente la enseñanza tradicional? A este respecto, Francisco Larroyo manifiesta el siguiente concepto:

«La enseñanza tradicional no es otra cosa que transmitir, por parte del maestro, conocimientos, y el aprender, paralelamente, la recepción, por parte del alumno, de estos conocimientos» ${ }^{45}$.

Así pues, dentro de este sistema de enseñanza tradicional, el profesor pareciera ser que es el único que posee de antemano el conocimiento; saber que transmite a los alumnos en forma autoritaria, a quienes considera como cosas y no sujetos. De esta manera los alumnos, a través de una conducta pasiva y receptiva, repiten de memoria la información expresada por el profesor ${ }^{46}$.

Igualmente cabe destacar que en el sistema de enseñanza tradicional del Derecho se deja sentir la influencia soberana de la clase magistral. Al respecto, Toledo González expresa lo siguiente:

«El método magistral o catedrático que como sistema globalizador de enseñanza ha venido rigiendo en facultades y escuelas de Derecho tiene su origen en la llamada enseñanza libresca que privó durante la Edad Media. Dentro de este método se concibe la enseñanza como un señalamiento o transmisión de conocimientos, al maestro como un informador o transmisor y al alumno como un objeto de enseñanza» ${ }^{47}$.

Por su parte, José Vernengo, al describir, analizar y criticar la exposición oral, manifiesta que:

«La clase magistral o exposición oral como institución de la enseñanza universitaria, pero también como técnica corriente de aprendizaje en los niveles terciarios, ofrece características paradójicas. De alguna manera, la clase magistral es vista como sucedáneo verbal del libro, en donde el profesor debe aparentar o contar con conocimientos más amplios de los que expone. Además, el profesor debe dominar cierto estilo retórico propio del lenguaje técnico de la disciplina, acompañado de cierta mímica tradicional en la que se refleja la autoridad magistral. También se exige

${ }^{45}$ F. Larroyo, Didáctica General Contemporánea, 6. ${ }^{a}$ ed., México DF, Porrúa, 1979, p. 69. ${ }^{46}$ Ibid., p. 69.

47 V. Toledo GonzÁlez, El proceso de enseñanza aprendizaje del Derecho, tesis para optar por el grado académico de maestro en Derecho de la Universidad Autónoma de México, México, 1976, pp. 218-219. 
de él un control severo de la emotividad. Es así como el profesor recita trozos selectos de su texto ante el auditorio que, más que nada, ha venido a oír de boca del maestro lo que podría leer en su casa. Es decir, los alumnos reciben pasivamente la comunicación, limitándose su papel al de simples receptores de informaciones. Además, difícilmente la clase magistral permite despertar la capacidad crítica del estudiante e inhibe el cambio» ${ }^{48}$.

Es bien cierto que la exposición oral improvisada y expuesta por profesores carentes de una cultura jurídica suficiente se vuelve en el absurdo más grande del proceso enseñanza-aprendizaje. Sin embargo, debemos ser objetivos y puntillosos en el análisis y en la crítica de la clase magistral. A este respecto, N. Abbagnano y A. Visalberghi consideran que la clase magistral surge en el ambiente de la escolástica estrechamente ligada a la actividad didáctica de los maestros medievales.

Dicha actividad se desenvolvía de dos maneras: la Lectio, que consistía en el comentario de un texto, y la Disputatio, que consistía en el examen de un problema mediante el debate de todos los argumentos que pudieran aducir en pro o en contra ${ }^{49}$.

Durante los siglos XIX y XX, la estructura curricular de los estudios de Derecho en nuestro país no ha permanecido estática, sino que ha cambiado al correr de los años. Entre otras razones cabe hacer mención de los impactos que se han generado con las transformaciones políticas, sociales, económicas, culturales e ideológicas.

Así pues, las modificaciones curriculares se reflejan tanto en el nombre de las asignaturas como en sus contenidos, además de en sus parámetros referentes a los perfiles de ingreso, permanencia y egreso de sus estudiantes y docentes.

Por otra parte, cabe destacar que la presencia centralista de la metrópoli ha influido en el diseño de los planes de estudios. Dicha tendencia sobrevivió hasta finales de la década de los ochenta del siglo Xx. A partir de ese entonces observamos que se han generado cambios curriculares en forma más dinámica en las diferentes instituciones de educación superior de las distintas entidades federativas.

48 Cfr. R. J. Vernengo, Estructura y función de la clase magistral, México DF, UNAM, 1977, pp. 3, 7, 8, 10, 13, 19 у 28.

${ }_{49}$ Cfr. N. Abbagnano y A. Visalberghi, Historia de la pedagogía, trad. de Jorge Hernández Campos, 1. ${ }^{a}$ ed. español, 1954 (5. ${ }^{a}$ reimp., México DF, Fondo de Cultura Económica, 1980, pp. 155-156). 
Sin el ánimo de agotar en este apartado dichas transformaciones de la educación jurídica en todo lo ancho y largo de la República mexicana durante el largo periodo de los siglos XIX y XX, sino únicamente con el propósito de dar al lector de la presente investigación un brevísimo esquema de los estudios de Derecho en México, a continuación se describe un panorama de los diferentes estadios históricos en que se puede analizar la evolución de la cultura jurídica en nuestra patria.

En el primer periodo se identifican criterios de una concepción jurídica imbuida del Derecho natural y canónico principalmente durante los siglos XVI, XVII, XVIII y principios del XIX. Al respecto basta citar, entre otras asignaturas, las siguientes: Prima de Cánones, Decreto, Código Sexto Clementinas, Derecho Natural, Derecho Romano, Derecho de Gentes, Derecho Civil e Impregnados de la Lengua Latina.

El tercer periodo comprende los años de 1867 a 1907. En esta etapa los planes de estudio de la carrera de Derecho se amplían y diversifican las asignaturas del Derecho Privado y Derecho Público, cuatro cursos de Derecho, Derecho Mercantil, Derecho Constitucional, Derecho Penal, Derecho Administrativo, Derecho Procesal, Derecho Internacional, Sociología, etc.

Durante esta etapa la concepción positivista de la exégesis del Derecho se consolida.

Con la llegada del proceso independentista en que se ve involucrada la Nueva España se recibe el impacto de la hegemonía francesa.

Consecuentemente, a partir del siglo XIX se genera, por una parte, la época de la sistematización del Derecho positivo y, por la otra, en México se establece el modelo de la universidad napoleónica, que tiene como propósito fundamental generar profesionistas liberales dedicados a conservar su statu quo.

Así es como llegamos al siglo XXI, con la presencia de las grandes codificaciones. Cabe recordar el Código de Napoleón de 1804, el cual trae aparejado el surgimiento y desarrollo de la concepción positivista de la exégesis del Derecho, en donde aflora la cultura de lo que el legislador dijo — «dicho está y lo que ha callado, callado está» o «yo no enseño el Derecho civil, sino únicamente el Código Civil»—. Tales expresiones, al igual que otras, construirán las estructuras del pensamiento de los estudiosos del Derecho y de los que en un futuro más que formarse seguirán en un proceso deformativo y autoritario que se verá reflejado también en las aulas universitarias, así como en los distintos espacios profesionales: ejercicio de la abogacía, administración y procuración de la justicia, etcétera. 
A mediados del siglo xx se inicia una mayor difusión de los estudios de licenciatura en Derecho en todos y cada uno de los Estados de la República mexicana. Empero, es en la década de los ochenta cuando se incrementan las ofertas académicas de los estudios tanto de licenciatura como del posgrado de Derecho por las instituciones privadas, entre otras razones por la imposición de las políticas económicas neoliberales, ya que el presupuesto para la educación superior pública se limita y se dan más facilidades para impulsar la educación privada. Además, éstas no requieren de grandes inversiones para su establecimiento. Consecuentemente, la calidad educativa no les interesa.

Actualmente, los nuevos paradigmas de la ciencia jurídica nos obligan a integrarnos a una dinámica del proceso enseñanza-aprendizaje más creativa y problematizadora del conocimiento jurídico. Entre otras razones cabe resaltar que, de acuerdo con las reformas constitucionales que se han realizado en nuestro país a partir del 18 de junio del 2008, donde se funda y motiva al sistema penal acusatorio con tendencia garantista, al igual que la reforma del 10 de junio de 2011, en donde el Derecho mexicano transita de un sistema legislativo local a una concepción más amplia de la normatividad jurídica del siglo XXI, ahora se demanda del estudiante de Derecho una concepción más amplia y compleja de su objeto de estudio que le permita acercarse a la transdisciplinariedad e interdisciplinariedad del conocimiento. Es impostergable que las nuevas generaciones de estudiosos de la ciencia jurídica se preocupen y ocupen por estudiar y analizar las diferentes corrientes teórico-metodológicas del Derecho, ya que el formalismo jurídico es una de tantas corrientes. Se requiere que los estudiosos del derecho se integren al paradigma del realismo jurídico, del estructuralismo jurídico y de la sociología jurídica aplicada. Por otra parte cabe resaltar que la práctica jurídica del siglo XxI exige una mayor aprehensión y profundización de las fuentes del Derecho, a fin de aminorar una práctica profesional excesivamente formalista de lo dado a través de la exégesis del Derecho. El reto y el desafío de las instituciones que ofertan los estudios de Derecho consiste en formar e informar dialógicamente a los estudiosos del Derecho a fin de lograr nuevas líneas de generación del conocimiento jurídico y de ampliar y problematizar su campo profesional a través de habilidades y competencias que le permitan aprender y comprender la argumentación jurídica a través de la aplicación de técnicas del proceso enseñanza-aprendizaje activas; por consiguiente, de métodos activos de enseñanza-aprendizaje del Derecho, los cuales les permitan transformar la 
docencia jurídica y lograr un mayor acercamiento a la investigación jurídica de frontera de práctica científica.

La enseñanza tradicional del Derecho basada en el comentario y análisis exegético de las normas jurídicas positivas vigentes: Constituciones, leyes generales, códigos, reglamentos, etc., generan estudiantes pasivos, receptivos, acríticos, que no cuestionan la cultura y el conocimiento disciplinario del Derecho; de ahí la presencia de muchos egresados de las escuelas de Derecho que en un alto porcentaje carecen de la formación e información necesaria para el desarrollo profesional de su disciplina y que, cada vez más, se alejan de las grandes metas que deben desarrollar los cultores de la ciencia jurídica para el efecto de generar conocimientos de frontera del mundo jurídico contemporáneo, en donde hace mucha falta la presencia de juristas y científicos del Derecho que fortalezcan la investigación jurídica de práctica científica, y de esa manera dar alternativas para los múltiples problemas sociales, económicos, políticos e ideológicos que se presentan actualmente de manera dramática, al igual que la falta de oportunidades de desarrollo impactan en la inseguridad pública, etcétera.

«A menor presencia de los métodos y las técnicas activas del proceso de enseñanza-aprendizaje del Derecho (preseminario, seminario, método del caso, método del planteamiento del problema, técnicas de investigación documental y de campo), menor será la formación de juristas y científicos del Derecho que fortalezcan la investigación jurídica, toda vez que la docencia tradicional no permite al estudiante adquirir los conocimientos, habilidades y competencias necesarias para argumentar y justificar de manera racional los diálogos, las discusiones y los debates académicos, ni tampoco cuestionar y problematizar el conocimiento que se obtiene a través de la repetición excesiva de la normatividad jurídica vigente. Es decir, reproducir la legislación positiva vigente a través de comentarios y análisis de los artículos que conforman una constitución, leyes generales y secundarias, memorizar y reproducir las codificaciones, reglamentos, decretos, entre otras, no es una actividad creativa que permita la generación del conocimiento. De ahí la escasez de alternativas coherentes y congruentes que demanda la sociedad del conocimiento jurídico del siglo XXI».

Consecuentemente, considero que estamos obligados a construir, conservar y desarrollar instituciones jurídicas que den respuestas a los grandes problemas locales, regionales, nacionales e internacionales. Ahora bien, el siglo XXI se identifica como la era de la sociedad del conocimiento científico, tecnológico y humanista. El cambio de paradigmas y la aparición de 
nuevos derroteros de la cultura y de la ciencia jurídica exigen una mayor participación creativa de sus cultores, así como de un mayor compromiso social para aminorar la creciente deshumanización que caracteriza a los profesionales liberales que sólo aspiran a conservar el statu quo y el ascenso social. Es por ello que la investigación jurídica es necesaria en cuanto a su conservación, difusión y fortalecimiento, toda vez que ahora debemos ver el Derecho desde una perspectiva plural y transdisciplinaria. Los indicadores que nos proporciona el SNI acerca de quiénes se dedican a la investigación de práctica científica en nuestro país nos permite, con conocimiento de causa, expresar que existen en la República mexicana demasiados abogados postulantes de corte liberal, y nos arroja un limitado número de aquellos que se ocupan de la investigación científica, que han sido evaluados y reconocidos por el Sistema Nacional de Investigadores a través del Consejo Nacional de Ciencia y Tecnología (CONACyT-SEP).

En México, la investigación jurídica de práctica científica es limitada, a pesar de que existe un universo de egresados de las facultades, escuelas e institutos de Derecho mayor a los 640.000 licenciados en Derecho. Sin embargo, es muy limitado el porcentaje de investigadores de la ciencia jurídica en México. Es decir, sólo existen 427 juristas reconocidos por el SNICONACyT. Por otra parte, cabe resaltar que la mayoría de los trabajos de investigación jurídica que se realizan descansan en la descripción e interpretación exegética de la legislación positiva vigente. Lo anterior se debe a que han sido formados bajo un esquema de enseñanza-aprendizaje memorístico, acrítico, reproductor, esto es, bajo el desfasado esquema de la enseñanza tradicional del Derecho.

En términos generales, no se advierte la generación de conocimiento jurídico de frontera, sino todo lo contrario, es repetitivo lo ya dado en la legislación en México. En ocasiones resulta obsoleta y muy limitada para las necesidades y retos que demanda la sociedad del conocimiento del siglo XXI.

\section{DIAGNÓSTICO ACTUAL SOBRE LA INVESTIGACIÓN JURÍDICA EN MÉXICO}

Durante muchos años se ha cuestionado acerca de ¿cuál es la función social de los estudiosos del Derecho?, por una parte, y, por la otra, ¿qué deben formar las escuelas, facultades y demás instituciones que ofertan los estudios de Derecho? A este respecto, Rafael de Pina ha expresado que la 
obligación de las universidades no consiste en profesionalizar, es decir, la universidad tiene como misión formar juristas y no conformarse en generar leguleyos, abogados postulantes, notarios, jueces, etc.

Hace ya muchos años, en un ensayo en torno a la formación profesional del abogado publicado en la Revista General de Legislación y Jurisprudencia (Madrid), en el número correspondiente al mes de febrero de 1930, escribíamos que la universidad no debe entregarse a la tarea de formar abogados, ni notarios, ni jueces, ni registradores de la propiedad, por ser ajena a su función propia y especifica. La universidad — afirmamos_ fracasará siempre que se le quiera dar el carácter de escuela profesional. La universidad será un centro de investigación de enseñanza apto para dar a sus alumnos una formación científica seria o no será más que una ficción. La preparación profesional, aunque otra cosa opinen eminentes profesores, debe quedar al margen de la actividad universitaria o, como máximo, considerarse ésta como una función accesoria. La universidad, en relación con la abogacía, prepara indirectamente para la actividad profesional, procurando a sus alumnos una formación jurídica sin la cual el abogado no será más que un agente de negocios más o menos hábil. El título de licenciado en Derecho es un antecedente necesario para los que pretendan ejercer la abogacía, pero la universidad no puede directamente darnos hecho al abogado ${ }^{50}$.

Así pues, para Rafael de Pina ser jurista significa, entre otras consideraciones, lo siguiente: «El jurista para nosotros es un científico del Derecho. Es el hombre que, en posesión de una cultura jurídica seria, está en condiciones de colaborar con el legislador en la creación del Derecho y en las que se precisan para interpretarlo, integrarlo y aplicarlo correctamente» ${ }^{51}$.

Por su parte, el doctor Héctor Fix Zamudio, hace más de treinta y cinco años, al reflexionar sobre la investigación jurídica se cuestionaba mediante la siguiente pregunta: ¿existe la investigación jurídica?, y daba como repuesta lo subsecuente:

«Las dudas que se han presentado tienen su origen en la falta de espectacularidad de la búsqueda de los datos de una disciplina normativa; búsqueda que no se traduce en descubrimientos sensacionales como los de la medicina, la química, la física o la astronomía $(v$. gr., la energía atómica, los trasplantes orgánicos o los progresos de la electrónica)».

${ }^{50}$ R. DE PINA, Pedagogía universitaria, op. cit., pp. 11 y 12.

${ }^{51}$ Ibid., p. 17. 
Los juristas se sienten desalentados frente a los resultados muy sólidos de otros campos del conocimiento, que se traducen en un progreso tecnológico muy acentuado; observan que con frecuencia las disposiciones jurídicas carecen de eficacia práctica, o bien que han sido superadas por la dinámica de la vida social.

Se advierte en los últimos años una preocupación muy profunda por la adecuación del ordenamiento jurídico al cambio social. Tratadistas de gran calidad científica dudan seriamente de la eficacia del ordenamiento jurídico para resolver los graves problemas derivados del subdesarrollo económico, político y social de Latinoamérica.

No obstante, sabemos que existe una ciencia jurídica, y que es posible realizar una búsqueda profunda en el enorme y cada vez más complejo campo del Derecho para lograr el perfeccionamiento de los ordenamientos normativos, para la regulación externa de la conducta humana, para una mejor convivencia social, mediante la construcción de sistemas, principios e instituciones que a su vez sirven de base para lograr posteriormente una búsqueda de nuevos datos tomados de la propia vida social, con el propósito de vincular la ciencia jurídica a las restantes disciplinas de carácter social ${ }^{52}$.

Por otra parte, me pregunto: ¿por qué no avanza la investigación jurídica en México? La problemática es compleja y complicada; se detectan, entre otras deficiencias, las siguientes: 1) la conservación y perpetuación de esquemas decimonónicos de la concepción del Derecho y del modelo de universidad napoleónica, que sólo genera, en el mejor de los casos, el egreso de profesionistas liberales que hacen de su profesión un ejercicio nemotécnico de la codificación; 2) ausencia de esquemas de conocimientos problematizadores sobre los contenidos jurídicos, parcelación del conocimiento, alejados de las visiones pluridisciplinarias, interdisciplinarias y transdiciplinarias del conocimiento jurídico; 3 ) carencia de estudiosos de las ciencias jurídicas y falta de infraestructura y material necesario para la investigación de la práctica científica del Derecho: acervos bibliográficos, hemerográficos, archivos judiciales, etc.; 4) falta de estímulos económicos y de reconocimientos académicos a quienes se dedican a tiempo completo a la investigación jurídica, a excepción de los que han logrado ingresar al Sistema Nacional de Investigadores.

52 Cfr. H. Fix-Zamudio, «Breves reflexiones sobre la enseñanza de posgrado y de la investigación en materia jurídica», en J. WitKer V. (coord.), Antología de estudios sobre la investigación jurídica, México DF, Coordinación de Humanidades-UNAM, 1978, pp. 210-211. 
Así pues, en el umbral del siglo Xxi la docencia e investigación jurídica presenta fuertes disfunciones ante los retos y desafíos que se han establecido en la era del conocimiento globalizado, finalmente sostenido por el avance de la informática y la cibernética. Por lo que es necesario desligarse, por una parte, de la concepción letrista y formalista de la exégesis del Derecho.

Ahora bien, cabe señalar que el Sistema Nacional de Investigadores fue creado el 26 de julio de 1984 para reconocer las actividades de las personas dedicadas a producir conocimiento científico y tecnológico. El reconocimiento se ha otorgado por medio de evaluaciones de pares, que permiten la emisión de un nombramiento de investigador con una distinción que simboliza la calidad de las contribuciones científicas y tecnológicas, otorgando de manera adicional un incentivo económico que premia el esfuerzo y la calidad del investigador ${ }^{53}$.

A continuación se mencionan algunos datos estadísticos sobre el Sistema Nacional de Investigadores. En enero del año 2014 había un total de 21.359 investigadores: 13.835 investigadores en los Estados de la República, lo cual representa el 64,8 por 100 del total, y 7.524 investigadores en el Distrito Federal, que representa el 35,2 por 100 del total, de los cuales 3.991 son candidatos, 11.637 del nivel I, 3.852 del nivel II y 1.843 del nivel III ${ }^{54}$.

Cabe destacar que en el área de Derecho se tienen identificados a más de 425 investigadores nacionales de un total de 652.000 profesionistas titulados de la licenciatura en Derecho ${ }^{55}$. Lo cual nos muestra que lo preocupante está en la falta de juristas, toda vez que un número muy reducido de licenciados en Derecho se interesan por la investigación jurídica debido a la enseñanza tradicional del Derecho, caracterizada por un sistema de enseñanza memorística, obsoleta y limitada práctica de investigación jurídica.

53 Diario Oficial, viernes, 21 de marzo de 2008. El Sistema Nacional de Investigadores encuentra su regulación previa en el Reglamento del Sistema Nacional de Investigadores publicado en el Diario Oficial de la Federación el 26 de septiembre de 2006, el cual fue modificado por última vez mediante acuerdo publicado en el Diario Oficial de la Federación el día miércoles, 26 de diciembre de 2012 [CONACyT-SNI, marco legal, Reglamento vigente 2013, http://www.conacyt.gob.mx/SNI/Documents/Reglamento_2013.pdf (fecha de consulta: 11 de marzo de 2013)].

54 Véase CONACyT, Sistema Nacional de Investigadores-Investigadores vigentes al 1 de enero de 2014, http://www.conacyt.mx/index.php/el-conacyt/sistema-nacional-de-investigadores (fecha de consulta: 11 de junio de 2014).

55 http://www.observatoriolaboral.gob.mx/ola/content/common/reporteIntegral/busqueda Reporte.jsf? idCarreraParametro $=3741$ EidTipoRegistroParametro $=1$ EidEntidadParametro $=3$ 3\#AnclaGrafica (fecha de consulta: 19 de marzo de 2013). 


\section{Investigadores eméritos ${ }^{56}$ del área jurídica}

En nuestro país, los investigadores eméritos de la ciencia del Derecho son los estudiosos de las disciplinas jurídicas que a lo largo de su brillante trayectoria académica de más de treinta años, y, en especial, de la investigación jurídica, han dejado su impronta al realizar investigaciones originales y que, además, han formado una corriente de pensamiento jurídico que tanto la comunidad nacional como internacional de los estudiosos de la ciencia del Derecho los reconocen. Sus investigaciones se han publicado en editoriales de prestigio nacional e internacional. Actualmente, hay ocho investigadores eméritos nacionales e internacionales.

\section{Investigadores nacionales de nivel III}

$\mathrm{Al}$ investigador nacional del nivel III se le otorga un reconocimiento que generalmente expresa lo siguiente: después de una revisión cuidadosa de su expediente y de ponderar sus logros científicos y académicos, en virtud de que demuestra una trayectoria de excelencia en materia de investigación científica y en el periodo objeto de evaluación reporta alta productividad con impacto internacional, participación en actividades de divulgación y en la formación de recursos humanos con la dirección de tesis de licenciatura y posgrado, la Comisión Dictaminadora del Área V, Sociales, en sesión plenaria y por decisión unánime, recomendó otorgarle el nombramiento de investigador nacional III. En el año 2014 se identificaron a treinta y siete investigadores nacionales del nivel III del área V, Ciencias Jurídicas y Derecho.

\section{REFLEXIONES FINALES}

La cultura jurídica mexicana es producto de un proceso de amplia aculturación en donde se reflejan los impactos e influencias antropológicas, sociológicas, económicas, políticas, culturales e ideológicas de un rico mosaico de mestizajes.

56 Investigador emérito significa que es un investigador aquella persona que estudia con profundidad, con claridad, precisión y en forma sistemática un objeto de estudio en forma disciplinaria, interdisciplinaria o transdisciplinaria. En cuanto a la calidad o distinción de emérito identificamos al profesor-investigador que ha acumulado experiencia teórica y práctica de su área de conocimiento por muchos años (más de treinta), en donde ha dejado su impronta en la investigación con reconocimiento nacional e internacional. 
En relación con la investigación jurídica, José Ramón Cossío expresa lo siguiente:

«En la investigación jurídica se realizan varias tareas pero, desafortunadamente, seguimos anclados al modelo dogmático del siglo XIX. La mayor parte de la investigación jurídica tiene la función de explicar textos legales y de exponer las características semánticas de los mismos. Por ello, la investigación que se hace en nuestro país consiste, básicamente, en la reconstrucción de textos legislados con el objeto de facilitar su conocimiento. En cuanto a la utilidad, creo que la más importante está en la docencia. Pienso que es el modelo estándar de investigación y exposición de reconstrucción de los textos jurídicos, aquél con el que se sostiene la enseñanza. La penetración que tienen los resultados de la investigación en las actividades cotidianas y en las de aplicación del Derecho apenas empieza a ser importante. Ya empieza a haber sentencias de la Suprema Corte y otros tribunales, en las que se citan doctrina y resultados de investigaciones jurídicas» ${ }^{57}$.

\section{Por su parte, María del Refugio González considera que:}

«El trabajo exegético que menciona el doctor Cossío yo ni siquiera lo consideraría de investigación, ya que no genera conocimiento» ${ }^{58}$.

Razón por la cual Miguel Pérez López expresa: «Antiguamente, nuestros investigadores estaban dedicados al trabajo de tipo exegético, de recuperación prácticamente arqueológica de los textos normativos» ${ }^{59}$. En tal virtud, mientras se siga en esos esquemas no lograremos realizar investigación de frontera, que proporciona alternativas de solución a los grandes problemas que hoy día se presentan.

Es por ello que Miguel Carbonell comenta:

«El reto no es solamente insertar el pensamiento jurídico de carácter teórico en las demandas y mutaciones que presenta la realidad circundante, sino convertir ese pensamiento en un marco referencial obligado para la toma de decisiones futuras. En otras palabras, necesitamos hacer que la investigación jurídica y sus productos sean relevantes para planear, dirigir, explicar y valorar los cambios que se están produciendo. Para ello debemos

${ }^{57}$ H. Fix Fierro (moderador), J. R. Cossío, M. ${ }^{a}$ del R. González, M. Díaz y Díaz y M. Pérez López (participantes), «Mesa redonda sobre la investigación jurídica en México», El Mundo del Abogado, año 2, núm. 7 (1999), p. 46.

58 Ibid., p. 48.

59 Ibid., p. 46. 
elevar notablemente los niveles explicativos y analíticos que manejamos. Se tienen que empezar a insertar muchos más referentes de control empírico en los resultados de nuestras investigaciones (por ejemplo, hay que acudir con mayor frecuencia a las encuestas de opinión o a las verificaciones fácticas de la aplicación de las normas; hay que diseñar instrumentos de medición de impacto de las disposiciones, de costos económicos, etcétera).

Si somos capaces de producir una dogmática que se aleje de las típicas reducciones academicistas (¿alguna vez han reparado en la cantidad de tiempo y esfuerzo que perdemos los abogados en disputas puramente terminológicas o nominales sin que haya ninguna cuestión de fondo que las justifique?), que se dedique a proporcionar soluciones concretas para problemas reales, estaremos entonces en posibilidades de incrementar no sólo la demanda de los servicios que presta la academia, sino también de mejorar el diálogo de los investigadores con los principales operadores jurídicos del país (tanto legisladores como jueces, abogados litigantes, notarios, ministerios públicos, etcétera)» ${ }^{60}$.

Después de haber expresado brevemente algunas consideraciones que nos permiten identificar en cierta forma el cómo surge, se conserva y desarrolla tanto la actividad docente y de investigación de los estudiosos del Derecho y de la difusión de la cultura jurídica mexicana, nos damos cuenta que gran parte de dicha problemática se identifica en los contenidos y en el cómo se desarrolla el proceso de enseñanza del Derecho en México, el cual raya en una docencia improvisada en términos generales, en donde el responsable de los cursos - profesor- no se encuentra informado y formado de manera integral para realizar la actividad educativa.

De ahí que se reproduzcan los esquemas de la enseñanza tradicional, vía el dictado de apuntes, imponiendo una cultura e ideología jurídica que en ocasiones ni el mismo profesor se ha detenido a reflexionar sobre ésta, toda vez que de manera mecanizada — vía la tortura de la memorización a ultranza de la información- se le tratará de domesticar al alumno en un ambiente acrítico, pasivo e irreflexivo, mediante el exagerado culto a la exégesis de la normatividad jurídica.

A este respecto, José Luis Soberanes Fernández expresa la siguiente reflexión:

«Como resultado del positivismo jurídico del siglo pasado y principios del presente, se pensó que el estudioso del Derecho tenía que almacenar

${ }^{60}$ Cfr. M. Carbonell, «Notas críticas y autocríticas sobre la investigación jurídica en México», El Mundo del Abogado, año 2, núm. 7 (1999), p. 55. 
en su memoria el contenido de todas las leyes en vigor para después aplicarlas al caso concreto, en un increíble ejercicio hermenéutico; de ahí que hasta hace poco tiempo se destacara el carácter memorístico de la carrera de Derecho, dado que el Derecho no está formado únicamente por leyes vigentes, sino por otras muchas cosas más. Frente a esa manera de contemplar el Derecho y al ver cómo recientemente el legislador ha sacado una ingente producción legislativa, resultaría absolutamente imposible registrar en la memoria tal cúmulo de disposiciones, de ahí que nuevamente se esté cayendo en cuenta que el verdadero jurista no es el que "sabe leyes, sino el capacitado para interpretar el Derecho", es decir, el que tiene criterio jurídico; por ello, la función de las facultades y escuelas de Derecho se contempla ya no tanto en dar información, sino dar formación a los que pretenden ser juristas» ${ }^{61}$.

Habida cuenta lo antes mencionado, nos percatamos que resulta muy difícil a los estudiantes de Derecho o a sus egresados presentar alternativas de solución para muchos de los problemas que se les presentan en su diario acontecer o los que se viven en nuestra realidad regional, nacional e internacional, en virtud de que, a través del modelo de la exégesis y de la docencia tradicional, al alumno lo han adiestrado para contemplar y ejecutar preceptos normativos sin antes reflexionar sobre el contenido de éstos; es decir, el qué intereses están en juego, a quiénes benefician y perjudican, y cómo se logran reproducir los esquemas hegemónicos de dominación.

Así pues, a través del dictado de apuntes vemos como el alumno se deforma en un ser repetitivo y no pensante, y cada vez más alejado para realizar la crítica y autocrítica de lo que se le informa; consecuentemente, su actividad es producto del reflejo condicionado, tiene temor y, sobre todo, salta a la vista su angustia cuando se le exige que piense por él mismo, que reflexione y problematice el conocimiento jurídico. Ahora bien, difícilmente el alumno lo hará mientras esté atado al modelo tradicional de la enseñanza del Derecho, ya que se le ha enseñado para no pensar; en cambio, sí para fortalecer la dependencia, el verticalismo y la intolerancia. De ahí que más adelante reproduzca el esquema del sometimiento.

Al respecto, Gladis S. Álvarez considera que:

«Esta relación de sometimiento encuentra su patrón en las relaciones familiares arcaicas. Alusiones tales como "la maestra es la segunda madre" tornan explícita la prolongación del paternalismo familiar en el aula. De

${ }^{61}$ J. L. Soberanes FernÁndez, Historia del sistema jurídico mexicano, op. cit., p. 10. 
esta manera, el rol del profesor en la enseñanza tradicional, en el mejor de los casos, cumple con la función de una monarquía benevolente, en el peor, una pequeña dictadura.

Por su parte, el rol del alumno en su calidad de receptor de la información lo lleva a una situación pasiva que ha sido comparada con una esponja o un buzón. Lamentablemente, esta actitud pasiva es incompatible con la democratización de la educación, que exige una participación cada vez mayor en el proceso de aprendizaje acorde con la participación que se le exigirá en la sociedad» ${ }^{62}$.

En ese orden de ideas es válida la reflexión que nos proporciona Chaïm Perelman al decir:

«En una sociedad democrática es imposible mantener la visión positivista (exegética), según la cual el Derecho no es otra cosa que la explicación arbitraria de la voluntad del soberano. Para funcionar eficazmente, el Derecho debe ser aceptado y no sólo impuesto por medio de la coacción» ${ }^{63}$.

Así pues, la educación alternativa es aquella que considera una relación dialéctica entre el educando y el educador. En donde existe la preocupación de establecer un proceso de enseñanza-aprendizaje dinámico, activo, participativo, creativo y generador de inquietudes permanentes para la búsqueda del conocimiento que se confronta con el quehacer cotidiano de la realidad que nos circunda.

Consecuentemente, a través de una concepción dialéctica de la educación se logrará informar y formar a un ser humano seguro de sí mismo, que no tenga miedo a la libertad del pensamiento y de concebir una realidad social más justa y humana en el sentido amplio de la palabra.

Ahora bien, después de haber expresado algunas consideraciones en relación con las vicisitudes de la enseñanza tradicional del Derecho cabe destacar que hoy en día es incuestionable e inaplazable el establecimiento y desarrollo de un proceso de enseñanza-aprendizaje dinámico del Derecho. Esto es, imprimirle a la docencia jurídica un carácter creativo y problematizador.

${ }^{62}$ Cfr. S. Álvarez, Gladys, Nuevos sistemas de enseñanza jurídica, ponencia presentada en la X Conferencia de Facultades, Escuelas e Institutos de Derecho de América Latina, México DF, Facultad de Derecho de la UNAM, 1986, p. 67.

${ }_{63}$ C. Perelman, Tratado de la argumentación. La nueva retórica, trad. de Luis Diez Picazo, Madrid, Civitas, 1979, p. 65. 
De esta manera vamos a descubrir que el posgrado de Derecho en México no logra ser un puente real para el fortalecimiento de la investigación jurídica, entre otras razones por las siguientes:

- Los alumnos de la licenciatura en Derecho llegan al posgrado con grandes deficiencias tanto de información como de formación. En ocasiones hasta el extremo de no acreditar un mínimo de lectura y de estudios, razón por la cual ya hace mucho tiempo que los egresados de las instituciones que ofrecen los estudios de Derecho perdieron el liderazgo intelectual, así como una creciente desvaloración de la profesión, de la cultura jurídica y de su actividad académica e investigación jurídica.

- Por otra parte, cabe destacar que la eficiencia terminal de los estudios de posgrado en Derecho en nuestro país es muy limitada, toda vez que gira alrededor del 10 al 17 por 100 en relación con sus graduados. Dicho dato es un claro indicador que nos refleja también las deficiencias que se viven respecto a la eficiencia terminal de los programas de la licenciatura en Derecho, la cual, según datos estadísticos del Anuario Estadístico de ANUIES de 2011, los alumnos que se titulan de alrededor de una población total de 211.793 es el equivalente a 29.555 , o sea, al 13,95 por $100^{64}$.

- En relación con la disponibilidad de tiempo por parte de los alumnos cabe hacer mención que, en términos generales, se puede considerar que no es de tiempo completo ni de medio tiempo. Además, es necesario estimar lo siguiente: hasta el momento no existen programas coherentes y congruentes que se hayan diseñado por parte del SEP-CONACyT para apoyar dignamente a los estudiantes del posgrado, toda vez que cuando son sometidos los programas de posgrado de Derecho de nuestro país a evaluación por dichas instituciones, los resultados que se obtienen respecto al cumplimiento que se establecieron en sus parámetros evaluativos no logran alcanzar ni un 40 por 100 de los mismos. Razón por la cual, pareciera ser que los criterios de evaluación se proyectaron de acuerdo con otras realidades muy ajenas a las que se viven en nuestro país, y, sobre todo, en provincia, en donde se percibe con claridad la falta de infraestructura documental y humana. Dicho de otra manera, ha sido muy difícil para los posgrados de las entidades federativas contar con bibliotecas y hemerotecas dignas que tengan un mínimo de títulos diferentes mayor a los 20.000 volúmenes, ya que si analizamos la realidad de los posgrados en cuanto a

${ }^{64}$ Cfr. ANUIES, Información y servicios/Información estadística de educación superior/Anuario estadístico de educación superior 2011. Fuente de información: bttp://www. anuies. $m x /$ content.php?varSectionID=166 (fecha de consulta: 20 de diciembre de 2012). 
sus bibliotecas nos damos cuenta que sus acervos aproximadamente tienen no más de 8.000 títulos diferentes; en tal virtud, si comparamos dichos acervos con el que tiene la biblioteca del Instituto de Investigaciones Jurídicas de la UNAM, no rebasan ni el 8 por 100.

- Además, no se cuenta con claustros académicos propios altamente cualificados. A este respecto cabe resaltar que, formar una planta docente y de investigadores ha representado y seguirá representando para la provincia un proceso lento, angustiante y de frustración, en virtud de que en nuestro país iniciamos la carrera hacia la modernización de la planta docente y de la investigación científica, tecnológica y humanista hace poco menos de cuarenta años, y en concreto, cuando hablamos de la disciplina del Derecho, y sobre todo en provincia, el tiempo se acorta, es menor, podríamos decir que hablamos de hace unos veinte a veintidós años cuando empiezan a desarrollarse los programas antes mencionados. Lo antes expresado se encuentra sustentado si tomamos en consideración la referencia tan significativa que fue citada respecto al número de investigadores de la disciplina jurídica que se encuentran reconocidos por el Sistema Nacional de Investigadores y que su adscripción está en la provincia.

- Considerando la información anterior, estimo, al igual que otros, que los criterios de evaluación tanto de la CIEES de la SEP como del CONACyT deben ser más congruentes y coherentes a la realidad nacional y, sobre todo, de las asimetrías que se viven en provincia, ya que en las entidades federativas se adolece de muchas carencias, y de esa manera comprender por parte de dichos organismos la necesidad sine qua non de previamente fortalecer a los programas de posgrado con recursos económicos significativos para el efecto de establecer y poner en práctica una planeación con programas operativos a mediano plazo (cinco años) para alcanzar un mínimo de infraestructura documental y humana. Y, de esa forma, fortalecer la investigación jurídica que tanta falta hace en el país.

- Consecuentemente, es necesario aplicar en la práctica y no abusar de la retórica en el discurso, el hacer realidad presupuestos de mayor apoyo económico para el desarrollo de las universidades públicas de provincia al efecto de fortalecer la educación superior: licenciatura y posgrado de Derecho (especialidad, maestría y doctorado). Igualmente, se requiere de un presupuesto ampliado e independiente para el fortalecimiento de la investigación jurídica, cuyos recursos se destinen para el establecimiento de programas que tengan que ver con el reconocimiento académico, económico y social para quienes se dedican a la investigación jurídica. 
Al respecto, José Ramón Cossío comenta:

«El problema es de tipo estructural. No tenemos comunidades científicas porque el conocimiento y la investigación generan poco prestigio y pocos ingresos. Como no tenemos un prestigio social, por una parte, por otro lado, no tenemos un ingreso. Tampoco tenemos la posibilidad de escalar en una jerarquía universitaria. Un investigador de la universidad de Harvard gana lo mismo que un ministro de la Suprema Corte de Estados Unidos. Tiene expectativas para moverse dentro de la cadena académica. Sabe que sus publicaciones no deben ser cuantitativas; que con uno o dos artículos al año, la comunidad considera su perspectiva, pero, claro, hay una comunidad que está atenta a lo que lee. Es una comunidad crítica y una comunidad en la que se influye. Esto, en México, casi no existe» ${ }^{65}$.

\section{Por su parte, Martín Díaz y Díaz expresa que:}

«El hecho de que en las universidades públicas existan investigadores que no investigan, o docentes que no enseñen, que vivamos un mundo de ficción en el medio académico profesional, se debe al problema estructural del que hablaba el doctor Cossío» ${ }^{66}$.

- Es por ello que existen en nuestro país pocos investigadores que se dediquen con seriedad a la actividad académica y a la investigación jurídica, la cual se convierte, para quien lo realiza con honestidad y profesionalismo, en un vivir lleno de penurias y de serias privaciones tanto para el investigador como para su familia. Con relación a esto, quienes lo hacen de esa manera forman parte de un reducido grupo de «incomprendidos» por la mayoría que no se encuentran en ese supuesto, y que sobre todo son los que a veces cuestionan sin ningún miramiento la actividad de la investigación jurídica. Es decir, la proveniente de los cultores de las llamadas «ciencias exactas o naturales», que desde otra perspectiva, hoy día a éstos les alcanza la agitación metodológica y duda de sí, ya que nada es definitivo, toda vez que está condicionado por un contexto temporal, a su vez sujeto a mutación. Todo aquello con lo que aún se viste a las matemáticas, su carácter absoluto y su perfecta exactitud, su generalidad y su autonomía, en una palabra, su verdad y su eternidad, todo ello —y perdón por la

${ }^{65}$ H. Fix Fierro (moderador), J. R. Cossío, M. a del R. González, M. Díaz y Díaz y M. Pérez López (participantes), «Mesa redonda sobre la investigación jurídica en México», op. cit., p. 49.

${ }^{66}$ Ibid. 
expresión- no es más que pura superstición ${ }^{67}$. Lo antes mencionado también se lo hacemos llegar a quienes se ufanan de tener un quehacer científico de sus disciplinas ( $v$. gr., sociólogos, politólogos, economistas, historiadores, antropólogos, lingüistas, etc.); que con cierta frecuencia expresan comentarios que desvalorizan la actividad de los juristas y teóricos de la ciencia del Derecho. Sin embargo, el clímax del drama de la incomprensión es aún mayor cuando se expresan descalificaciones por parte de los profesionistas de nuestra disciplina del Derecho que muchas de las veces lo hacen por su ignorancia y mala fe que les acompaña.

- Al continuar con nuestras reflexiones sobre la investigación jurídica que se realiza en nuestro país (México) aterrizamos en las disparidades asimétricas que generan y acompañan a la pobreza, desarrollo e investigación jurídica, toda vez que identificamos, por una parte, que la investigación como actividad fecunda se localiza en la Ciudad de México DF, a través de lo que realiza y representa sobre todo el Instituto de Investigaciones Jurídicas de la UNAM, sin lugar a dudas el lugar donde se localiza la mayor producción de la investigación jurídica que se realiza no sólo en México, sino en otras latitudes del mundo, y por la otra, cabe hacer mención de los indicadores que nos permiten explicar y justificar el desarrollo que a lo largo de sus sesenta años ha alcanzado dicho instituto, que son, a saber:

- No existe en provincia ningún centro o instituto de investigaciones jurídicas que tenga la infraestructura material y humana. Así pues dicho Instituto cuenta con un número aproximado a los 92 investigadores, de los cuales 26 son investigadores nacionales de nivel III, 24 de nivel II y 16 de nivel I (la mayor parte de estos investigadores se encuentra en el instituto ya referido y se comparte una menor con los que tienen adscripción en la Facultad de Derecho de la UNAM).

- La continuidad en el liderazgo por parte de los directores del referido Instituto. A este respecto basta citar previamente a don Niceto Alcalá-Zamora y Castillo, egregio jurista hispano e investigador fundador de dicho Instituto, y enseguida citar, entre otros destacados directores, a los subsecuentes: Felipe Sánchez Román y Gallifa, Raúl Carrancá y Trujillo, Mario de la Cueva, Antonio Martínez Báez, Roberto L. Mantilla Molina, César Sepúlveda, Héctor Fix-Zamu-

${ }^{67}$ Cfr. A. Hernández Gil, La ciencia jurídica tradicional y su transformación, 1. a ed., Madrid, Civitas, 1981, p. 94. 
dio, Jorge Carpizo, Jorge Madrazo, José Luis Soberanes Fernández y Diego Valadés ${ }^{68}$.

- Producción bibliográfica y hemerográfica ininterrumpida por más de sesenta años.

- Acervo bibliográfico mayor a los 150.000 volúmenes, lo que significa más de 85.000 títulos diferentes. Igualmente se complementa con el acervo bibliográfico de la biblioteca de la Facultad de Derecho de la UNAM con más de 300.000 volúmenes, dando un total aproximado de más de 100.000 títulos diferentes; además, el Instituto mantiene un intercambio de más de 400 revistas de todo el mundo al año.

- Por último, sólo me resta expresar que el posgrado de Derecho en México debe ser fortalecido a través de presupuestos que se apliquen para el desarrollo y fortalecimiento de la infraestructura documental (bibliotecas, hemerotecas, centros de legislación y jurisprudencia, materiales didácticos tanto tradicionales como de alta tecnología), enriquecimiento de la infraestructura humana para la formación de docentes investigadores calificados, para el efecto de que éstos obtengan reconocimiento académico social y apoyos económicos. También establecer programas de becas dignos para los estudiantes y garantizar a los egresados más destacados incorporación segura en la docencia e investigación jurídicas en sus centros de estudios. Ahora bien, si logramos dar cumplimiento a las propuestas antes expresadas, se podrán aceptar racionalmente las políticas de evaluaciones a los posgrados de Derecho en nuestro país por parte de la CIEES y del CONACyT. De lo contrario, si se siguen practicando las evaluaciones como actualmente lo hacen, resultan éstas un quehacer desgastante, infructuoso y frustrante para las instituciones públicas evaluadas, ya que generalmente sus resultados no logran satisfacer los requisitos que se establecen como parámetros establecidos por estos organismos, y, en consecuencia, los programas evaluados no reciben apoyos económicos, en cambio sí se les da una calificación de sus irregularidades.

- A pesar de todo lo que se ha expresado, no hay duda alguna ya que hasta este momento las universidades públicas e instituciones de educación superior del Estado son la base fundamental de la escasa y poco reconocida investigación jurídica que se realiza en provincia.

${ }^{68}$ Instituto de Investigaciones JuRídicas, Sexagésimo Aniversario, 1940-2000, 1. a ed., México DF, Instituto de Investigaciones Jurídicas de la UNAM, 2000, p. 455. 


\section{BIBLIOGRAFÍA}

Abbagnano, N., y Visalberghi, A., Historia de la pedagogía, trad. de Jorge Hernández Campos, 1. ${ }^{a}$ ed. español, 1954 (5. ${ }^{a}$ reimp., México DF, Fondo de Cultura Económica, 1980).

ADAmE GODDARD, J., «Los manuscritos jurídicos latinos de la Biblioteca Nacional», en Memoria del IV Congreso de Historia del Derecho Mexicano, Serie C, Estudios Históricos, núm. 25, 1. ${ }^{\text {a }}$ ed., México DF, Instituto de Investigaciones Jurídicas, UNAM, 1988.

ÁlvareZ, G. S., «Nuevos sistemas de enseñanza jurídica», ponencia presentada en la X Conferencia de Facultades, Escuelas e Institutos de Derecho de América Latina, México DF, Facultad de Derecho de la UNAM, 1986.

Badenes Gasset, R., Metodología del Derecho, Barcelona, Bosch, 1979.

Barrientos Grandon, J., La cultura jurídica en la Nueva España, 1. ed., México DF, Instituto de Investigaciones Jurídicas de la UNAM, 1993.

Carbonell, M., «Notas críticas y autocríticas sobre la investigación jurídica en México», El Mundo del Abogado, año 2, núm. 7 (1999).

De la Plaza y Jean, C. B., Crónica de la Real y Pontificia Universidad de México, siglo XVII, 2 tt. (479 y 300 pp.). Con apéndice (490pp.), versión paleográfica, proemio, notas y apéndice por N. RANGel, 1. ${ }^{a}$ ed., México DF, UNAM, 1931.

De Pina, R., Pedagogía universitaria, México, Ediciones Botas, 1960.

Fix Fierro, H. (moderador); Cossío, J. R.; González, M. ${ }^{a}$ del R.; Díaz y Díaz, M., y Pérez López, M. (participantes), «Mesa redonda sobre la investigación jurídica en México», El Mundo del Abogado, año 2, núm. 7 (1999).

Fix-ZAmudio, H., «Breves reflexiones sobre la enseñanza de posgrado y de la investigación en materia jurídica», en J. WITKER V. (coord.), Antología de estudios sobre la investigación jurídica, México DF, Coordinación de Humanidades-UNAM, 1978.

Hernández Gil, A., Metodología de la ciencia del Derecho, vol. I, 1. a ed., Madrid, Gráficas Unguina Meléndez Valdez, 1971.

- Problemas epistemológicos de la ciencia jurídica, 2. ${ }^{a}$ ed., Madrid, Civitas, 1976.

- La ciencia jurídica tradicional y su transformación, 1. ${ }^{a}$ ed., Madrid, Civitas, 1981.

Jiménez Rueda, J., Las Constituciones de la antigua universidad, México DF, UNAM, 1951.

Lafragua, J. M. ${ }^{a}$, Arenga cívica pronunciada el día 27 de septiembre de 1843 en la alameda de México, Memoria de la gloriosa consumación de la independencia de México, México DF, Imprenta de Torres, 1843.

Larroyo, F., Didáctica general contemporánea, 6. ${ }^{a}$ ed., México DF, Porrúa, 1979.

Margadant Floris, G., Introducción a la Historia del Derecho Mexicano, 11. ${ }^{a}$ ed., México DF, Esfinge, 1994. 
Perelman, C., La lógica jurídica y la nueva retórica, trad. de Luis Díez-Picazo, Madrid, Civitas, 1979.

- Tratado de la argumentación. La nueva retórica, trad. de Luis Diez Picazo, Madrid, Civitas, 1979.

SÁnchez VÁzquez, R., «Vida y obra de José María Lafragua y la Biblioteca José María Lafragua de Puebla», en Anuario Mexicano de Historia del Derecho, t. VII, México DF, Instituto de Investigaciones Jurídicas de la UNAM, 1995.

Soberanes Fernández, J. L., Historia del sistema jurídico mexicano, 1. ${ }^{a}$ ed., México DF, Instituto de Investigaciones Jurídicas de la UNAM, 1990.

Toledo GonzÁlez, V., El proceso de enseñanza aprendizaje del Derecho, tesis para optar por el grado académico de maestro en Derecho de la Universidad Autónoma de México, México DF, 1976.

VERNENGO, R. J., Estructura y función de la clase magistral, México DF, UNAM, 1977.

Villoro, L., La revolución de independencia. Historia General de México, t. 2, 2. ${ }^{a}$ ed., México DF, El Colegio de México, 1977.

\section{Otras fuentes}

ANUIES, Información y servicios/Información estadística de educación superior/Anuario estadístico de educación superior 2011. Fuente de información: http://www.aniies. $m x /$ content.php? varSectionID $=166$ (fecha de consulta: 20 de diciembre de 2012).

CONACyT-SNI, marco legal, Reglamento vigente 2013, http://www.conacyt.gob. $m x / S N I / D o c u m e n t s / R e g l a m e n t o \_2013 . p d f$ (fecha de consulta: 11 de marzo de 2013).

Diario Oficial, 21 de marzo de 2008.

bttp://www.observatoriolaboral.gob.mx/ola/content/common/reporteIntegral/busque daReporte.jsf?idCarreraParametro=3741EidTipoRegistroParametro=1EidEntid adParametro=33\#AnclaGrafica (fecha de consulta: 19 de marzo de 2013).

Instituto de Investigaciones Jurídicas, Sexagésimo Aniversario, 1940-2000, 1. ${ }^{a}$ ed., México DF, Instituto de Investigaciones Jurídicas de la UNAM, 2000. 